\title{
Experimental and theoretical analyses of temperature polarization effect in vacuum membrane distillation
}

\author{
Ahmad S. Alsaadi, Lijo Francis, Gary L. Amy, Noreddine Ghaffour \\ Water Desalination and Reuse Center, King Abdullah University of Science and Technology (KAUST), 23955-6900 \\ Thuwal, Saudi Arabia, Tel. +966-28082180, Email: noreddine.ghaffour@kaust.edu.sa
}

\begin{abstract}
This paper discusses the effect of temperature polarization in Vacuum Membrane Distillation (VMD). The main motivation for using VMD in this work is that this module configuration is much simpler and more suitable for this kind of investigation than the other MD configurations such as Direct Contact Membrane Distillation (DCMD). The coupling between heat and mass transfer mechanisms at the feed-membrane interface is presented from a theoretical point of view. In addition, a new simple graphical method and a mathematical model for determining VMD flux are presented. The two methods used in evaluating the extent of temperature polarization effect on water vapor flux (flux sensitivity factors and Temperature Polarization Coefficient (TPC)) are also analyzed and compared. The effect of integrating a heat recovery system in a large scale module on the TPC coefficient has also been studied and presented in this paper.
\end{abstract}

Keywords: Vacuum membrane distillation (VMD); Temperature polarization; Mass transfer coefficient; Heat transfer; Flux sensitivity factor. 


\section{Introduction}

One of the major drawbacks associated with all membrane separation processes is a physical phenomenon that takes place near the membrane surface referred to as polarization. This phenomenon is observed in the thin layer of liquid near the membrane interface once it under goes changes in mass and heat transfer. It is considered as one of the main limiting parameters of the membrane processes permeate and a major contributor to fouling/scaling formation on membranes surfaces. Depending on the applied driving force of the membrane system, the polarization phenomenon can be either temperature polarization or concentration polarization, as shown in Figure 1.

Figure 1: The two types of polarization phenomenon in membrane processes.

Concentration polarization takes place in both isothermal processes (e.g., reverse osmosis (RO) and forward osmosis (FO)) and in non-isothermal processes (e.g., membrane distillation (MD)). The polarization effect of this type is experienced as a form of concentration gradient once a membrane starts to segregate a fluid mixture into permeate and retentate.

Temperature polarization develops only in non-isothermal processes such as MD and results in a reduction of the driving force of the permeate flux when a thermal gradient is formed near the membrane surface. Since its proposed definition for the first time by Schofield et al. in 1987 [1], temperature polarization is considered as one of the main issues raised against MD development because it reduces the permeate flux significantly [2].

But since both types of polarization occur in the MD process, it is needed to discuss which type of these two phenomena has the most significant effect on the water vapor flux.

At first it is important to differentiate between the effect of "feed concentration" and the effect of "concentration polarization" on the flux. Addition of solute into pure water always alters its liquid-vapor equilibrium state and results in a reduction of its water vapor pressure which in turn reduces the MD flux. On the other hand, the concentration polarization effect represents only the fractional reduction in MD flux that is caused by the increase in feed concentration near the membrane surface. For instance, Fane et al. [3] conducted a parametric 
analysis of the effect of feed concentration on MD flux and found that for a near saturation concentration of $\mathrm{NaCl}$ solution, the $\mathrm{MD}$ flux was about $40 \%$ less than that of pure water. For similar feed solution concentration, Calabro and Drioli [4] found that concentration polarization reduced the MD flux by $4 \%$ only. The effect of concentration polarization is expected to be even lower for diluted solutions. Martinez et al. [5] reported that a concentration polarization of $4 \%$ will reduce the feed water vapor pressure by $0.2 \%$ only. In the same study, they concluded that the largest reduction of the flux is caused by temperature polarization and, to some lower degree, by the reduction of water vapor due to the concentration of the feed and to a negligible effect by concentration polarization.

The exponential behavior of the water vapor pressure with temperature may explain the reason behind the large effect of temperature polarization on MD flux. Therefore, this investigation will be focused on temperature polarization only.

As mentioned above, the first temperature polarization studies have been conducted by Schofield et al. [1] who laid the theoretical foundations of this phenomenon. In another paper, the same authors emphasized the importance of improving the MD module design through applying de-aeration and enhancing the heat transfer coefficient, and they highlighted that the MD flux is not controlled by the membrane structure resistance. On the other hand, Bandini et al. [6] analyzed the mass transfer resistance and the external heat transfer resistance of Vacuum Membrane Distillation (VMD) and found them to be equally important.

Another major work in the MD literature towards understanding the temperature polarization phenomenon was conducted by Martinez-Diez et al. [5, 7, 8], Rodriguez-Maroto and Martinez [9] and Martinez and Rodriguez-Maroto [10] who was built on Schofield et al. work [1]. They studied the temperature polarization effect in direct contact membrane distillation (DCMD) configuration, evaluated the relative effect of temperature and concentration polarizations on MD flux, introduced a new method for calculating the membrane thermal conductivity through DCMD thermal efficiency, and compared the effect of MD membrane resistance on the fluid film heat transfer resistance.

The last five years of MD literature showed a major shift in studying temperature polarization phenomenon. Researchers has taken advantage of the availability of powerful computers along with advanced Computational Fluid Dynamic (CFD) modeling packages and started to simulate the behavior of the fluid thin film near the membrane surface [11-19]. The 
central focus of these simulation studies has been to investigate the turbulence promoter's effect on the fluid temperature, velocity and pressure profiles near the membrane surface to see how these promoters could enhance the water vapor flux.

Conclusions drawn from these CFD studies are more or less qualitative while quantitative studies require experimental data to support theoretical findings. For the DCMD configuration, different experimental methods had been tried to measure the feed temperature at the membrane interface. For example, Sakai et al. [20] utilized the linear relationship found between the reciprocal of the stirring rate with the effective mass transfer resistance at constant $\Delta \mathrm{P}$ to calculate the permeability of the membrane at zero temperature polarization. They achieved this by extrapolating the linear curve to infinite stirring rate where the intercept with the y-axis represent the membrane mass transfer resistance at zero temperature polarization condition. However, the calculation of the temperature polarization effect by this method is based on the assumption that the membrane mass transfer resistance remains constant at different feed and permeate conditions which is not the case for the DCMD process. The membrane mass transfer in DCMD is a combination of Knudsen and molecular diffusion mechanisms and the change in fluid conditions changes the partial pressure of non-condensable gases inside the membrane pores which in turn changes the molecular diffusion resistance and the overall mass transfer resistance of the membrane. In a recent study, Ali et al. [21] designed a new DCMD cell that has 16 temperature sensors to measure the feed and permeate bulk temperatures as well as temperatures near the membrane surface. However, the physical presence of these sensors near the membrane is expected to induce local turbulence around them which cause the sensors to transmit higher temperature values than the actual ones. Thus, we believe that the DCMD configuration is not the best method to study the effect of temperature polarization because the probing of the fluid temperature at the membrane interface is very challenging in this configuration and it is subjected to high experimental errors. Alternatively, in this study VMD configuration is proposed to investigate temperature polarization. Unlike DCMD, the temperature polarization in VMD takes place at one side of the membrane only. Such a simple configuration helps in analyzing the temperature polarization phenomenon theoretically once the permeability of the membrane and the convective heat transfer coefficients are known.

The number of studies conducted on the VMD configuration represented $16.7 \%$ only of the MD literature by the end of 2010 [22]. For the past two years the VMD studies percentage were 
found to be even lower. Additionally, the VMD literature showed that the majority of the studies are mainly focused on testing VMD for new applications such as the removal of Volatile Organic Compounds (VOC) from aqueous solution [23-31], fermentation [32, 33], desalination [34-39] and juice concentration in food industry [40-46].

Very few studies have tried to analyze and understand the temperature polarization phenomenon in VMD $[6,47,48]$. The objective of this paper is focused on closing the knowledge gap of this issue. It discusses the heat and mass transfer resistances in the VMD process and gives detailed interpretation on how heat and mass transfer rates in VMD are coupled. It also describes a simple mathematical model for the VMD process that is used along with VMD experimental data to evaluate the heat and mass transfer coefficients of the process. Furthermore, a comparison between two methods used in this study in evaluating the temperature polarization effect on VMD flux is discussed as well.

\section{Theory}

Heat and mass transfer rates in a VMD process are coupled; which means that a change in one of these two rates will induce a change in the other. This coupling is discussed right after discussing the VMD heat and mass transport, separately.

\subsection{Mass transfer}

Mass transfer resistances in a VMD process are categorized into three types (Fig. 2):

Figure 2: Diffusive mass transfer resistance in (A) the liquid phase, (B) the gas phase, and (C) frictional mass transfer resistance through the membrane pores in VMD process.

A. Diffusive mass transfer resistance in the liquid phase: This type of resistance is caused by the concentration polarization of a relatively non-volatile component in a mixture near the membrane surface. The non-volatile components will accumulate at the entrance of the membrane pores and block the way of the relatively volatile components and prevent them from reaching the membrane interface. This resistance will force the volatile components to diffuse among the non-volatile components in order to reach the membrane interface. 
Bandini and Sarti [49] found that this mass transfer resistance is only important for the separation of the volatile organic compounds (VOCs) that are present in small concentration in an aqueous mixture. For the water vapor flux in pure water or a dilute salt solution, they reported that this type of resistance is not significant. Therefore, this mass transfer resistance will be neglected here because the experimental part of this work uses deionized water as feed solution.

B. Diffusive mass transfer resistance in the gas phase: At atmospheric pressure and before applying vacuum to the VMD process, membrane pores will be pre-occupied by noncondensable gases e.g., $\mathrm{N}_{2}$ and $\mathrm{O}_{2}$. These gases remain in the membrane pores and obstruct the way of the water vapor molecules and reduce their momentum towards the condensation side. Once low vacuum pressure is applied (lower than the saturation pressure of the feed temperature at the membrane interface), the partial pressure of these non-condensable gases becomes very small compared to the water vapor molecules inside the membrane pores. In such a case, the molecular diffusion mechanism is not playing a significant role and its resistance to the mass transfer inside the membrane pores is negligible as well.

C. Frictional mass transfer resistance through the membrane porous structure: This resistance is considered as the main mass transfer resistance of water vapor flux in the VMD process. Water vapor molecules that leave the liquid surface at the membrane interface encounter frictional mass transfer resistances inside the pore structure. The dominating type of mass transfer mechanism depends on the size of the pores available for the vapor molecules. The Knudsen's flow regime is expected to be dominating when the pore size is smaller than the mean free molecular path. In this regime, the vapor molecules collide several times with the polymeric molecules that make up the wall of the membrane pore (the frequency of collisions depends on the thickness of the membrane) before they reach the other side of the membrane. The water vapor mass flux of Knudsen flow $\left(\mathrm{J}_{\mathrm{k}}\right)$ can be calculated by the following equation: $\mathrm{J}_{\mathrm{k}}=1.064 \frac{\mathrm{r} \varepsilon}{\tau \delta}\left(\frac{\mathrm{M}}{\mathrm{RT}_{\text {avg }}}\right)^{0.5}\left(\mathrm{P}_{\mathrm{i}}-\mathrm{P}_{\mathrm{v}}\right)$

where $P_{i}$ and $P_{v}$ are the water vapor pressure at the feed-membrane interface and at the vacuum side of the membrane, respectively; r, $\varepsilon, \tau$ and $\delta$ are the average pore size, porosity, tortuosity and thickness of the membrane, respectively; and $\mathrm{M}, \mathrm{R}$ and $\mathrm{T}_{\text {avg }}$ are the molecular weight of 
water, universal gas constant and the average absolute temperature inside the membrane pores, respectively.

On the other hand, if the pore size of the membrane is greater than the mean free path, then the vapor transport is best described by Poiseuille's flow regime. The viscous forces among the water vapor molecules become much more important than their interaction with the walls of the membrane pores. In this regime, the mass flux of the water vapor $\left(\mathrm{J}_{\mathrm{p}}\right)$ is calculated by the following equation:

$$
\mathrm{J}_{\mathrm{P}}=0.125 \frac{\mathrm{r}^{2} \epsilon}{\tau \delta}\left(\frac{\mathrm{MP}_{\text {avg }}}{\eta \mathrm{RT}_{\text {avg }}}\right)\left(\mathrm{P}_{\mathrm{i}}-\mathrm{P}_{\mathrm{v}}\right)
$$

where $\eta$ and $P_{\text {avg }}$ are the viscosity of the water vapor and its average vapor pressure, respectively.

The question that we raise here is which one of these two mechanisms should be used to evaluate the water vapor mass flux through a VMD membrane? Lawson and Lloyd [50] applied both regimes in their modeling to the VMD and calculated the importance of Poiseuille's flow regime relative to Knudsen flow as:

$$
\xi=0.2 \frac{P_{a v g} r}{\eta^{\prime} v}
$$

where $\eta$ ' and $v$ are the gas viscosity and mean molecular speed of the water molecule, respectively.

Zhang et al. [51] also used both regimes in their modeling to the VMD process because they expected the process to operate in the transition region where both flow regimes will be important.

In another VMD modeling study, Lovineh et al. [52] neglected the Poiseuille's flow contribution and assumed Knudsen flow to be the dominating mass transfer mechanism. The linearity of Knudsen's flow equation along with the linear relationship confirmed experimentally $[6,47,52]$ between the water vapor mass flux and the partial pressure difference, supported by Lovineh et al. [52] modeling assumption.

\subsection{Heat transfer}

The surfaces at which evaporation and condensation take place are the most likely parts of the VMD system that cause its water vapor flux to be heat transfer limited. The large latent heat 
of the water vapor and the no-slip condition (zero viscous fluid velocity at the boundary of a solid surface) make it very difficult for the hydrodynamic conditions represented by $\mathrm{h}$ to meet the heat transported by evaporation and condensation. This heat transfer limitation appears in a temperature polarization form near these surfaces. The large latent heat of the water vapor is a natural physical property and nothing can be done toward reducing its effect on the heat transfer limitation. However, the no-slip condition effect can be mitigated by introducing turbulence promoters near these surfaces [2].

Since the no-slip condition exists at the condensation and evaporation surfaces of the VMD process, the convective heat equation can be used to calculate the heat transferred through these surfaces:

$Q=h\left(T_{b}-T_{i}\right)$

where $h$ is the convective heat transfer coefficient of the feed, and $T_{b}$ and $T_{i}$ are temperatures of the bulk and at the membrane interface of the feed, respectively. The heat transfer coefficient is a function of Reynolds number and some physical properties of the fluid. The method used in calculating the heat transfer coefficient has been reported in our previous work [53].

Energy is also transferred through thermal conduction. However, all researchers agreed on the validity of neglecting the contribution of this mechanism to the heat transfer in VMD.

Depending on the temperature of the feed at the membrane interface, energy is also transferred through the latent heat of water vapor according to the following equation: $Q=J g_{v}$

where $\mathrm{J}$ is the water vapor flux and $\mathrm{g}_{\mathrm{v}}$ is the saturated water vapor enthalpy.

\subsection{Heat and mass transfer coupling}

At steady state, the total energy balance of the VMD process is written as:

$Q=h\left(T_{b}-T_{i}\right)=J g_{v}=C_{m}\left(\mathrm{P}_{\mathrm{i}}-\mathrm{P}_{\mathrm{v}}\right) g_{v}$

where $C_{m}$ is the membrane mass permeability coefficient.

If we try to follow a logical train of thought along with some already known facts about heat and mass transfer as a mean to describe how a steady state in a VMD process could be reached, then we could narrate it as follow: 
Assuming that the VMD membrane pores are initially not under any partial pressure gradient then at the moment a hot feed comes into contact with the membrane surface, its temperature there $\left(T_{i}\right)$ will be equal to its bulk temperature $\left(T_{b}\right)$. $T_{i}$ is also expected to remain the same as long as there is no heat loss through the membrane surface neither by evaporation nor by heat conduction. Once vacuum pressure is applied to the other side of the membrane, water vapor molecules will be transported through the membrane pores towards the permeate side. This initial water vapor transfer rate depends on both the partial pressure difference made by the vacuum and on the mass transfer coefficient of the membrane to the water vapor $\left(\mathrm{C}_{\mathrm{m}}\right)$. The first molecules that leave the feed surface at the membrane interface will disturb the temperature homogeneity of the feed. $T_{i}$ will start to decrease creating a temperature gradient that causes additional heat to be driven from the bulk feed to the membrane interface. The effectiveness of the heat driving force depends on the hydrodynamics inside the feed channel and the physical properties of the feed which are all represented by the convective heat transfer coefficient (h). If we assume that the applied vacuum pressure at the permeate side remains constant, then the decrease of $T_{i}$ will also lower the partial pressure difference that drives the water vapor molecules through the membrane pores. $T_{i}$ will continue to decrease until it reaches an equilibrium value that makes the temperature gradient at the feed side high enough to drive heat from the bulk fluid equivalent to that lost by water evaporation. $T_{i}$ equilibrium temperature will be somewhere between $T_{b}$ and the saturation temperature of the vacuum pressure at the permeate side. $T_{i}$ approaches $T_{b}$ when $h$ approaches infinity. In this case, the VMD flux becomes limited by $\mathrm{C}_{\mathrm{m}}$. $\mathrm{T}_{\mathrm{i}}$ also approaches the saturation temperature of the vacuum pressure as $\mathrm{h}$ approaches zero which makes the process heat transfer limited. The former case is only achieved when the fluid starts boiling and the vapor is being generated from within the bulk fluid. The latter case can be observed in a VMD process that operates in a batch mode where the walls of the feed container are well insulated and no heat is being supplied to the fluid at the membrane interface. Figure 3 illustrates how $T_{i}$ at equilibrium affects the flux of a VMD process operating at constant $P_{v}$ and constant $T_{b} . P_{v}$ is assumed to be equal to the saturation pressure of pure water at $20^{\circ} \mathrm{C}$ while $\mathrm{T}_{\mathrm{b}}$ is assumed to be at $80^{\circ} \mathrm{C}$. For illustration purpose, the membrane permeability is also assumed to be equal to $0.0011 \mathrm{~kg} \mathrm{~m}^{-2} \mathrm{hr}^{-1}$. $\mathrm{Pa}$ [54]. The straight line in the graph denotes the water vapor mass flux as a function of $\Delta \mathrm{P}\left(\mathrm{J}=\mathrm{C}_{\mathrm{m}} \Delta \mathrm{P}\right)$ while the second curve represents the 
value of $\Delta P$ across the membrane pores at different equilibrium temperatures of $T_{i}\left(\Delta P=P_{v}-P_{i}\right.$, where $P_{i}$ is the vapor pressure at $T_{i}$ ).

Figure 3: A graphical method for calculation of water vapor flux at different $\mathrm{T}_{\mathrm{i}}$.

Assuming that the heat transfer coefficient is very large (approaches infinity) then $T_{i}$ will reach equilibrium at $80^{\circ} \mathrm{C}$ where from the blue curve $\Delta \mathrm{P}$ across the membrane will be about 45 $\mathrm{kPa}$. At this value of $\Delta \mathrm{P}$ the straight line curve gives us a water vapor flux of about $50 \mathrm{~kg} / \mathrm{m}^{2} . \mathrm{hr}$. When the heat transfer coefficient is very small then $T_{i}$ it will equilibrate at the lower end of the blue curve where the flux of water vapor will stop once $\mathrm{T}_{\mathrm{i}}$ reaches $20^{\circ} \mathrm{C}$ (the saturation temperature of the vacuum pressure applied). If $\mathrm{T}_{\mathrm{i}}$ equilibrates at $60^{\circ} \mathrm{C}$ then the water vapor flux will be about $20 \mathrm{~kg} / \mathrm{m}^{2} . \mathrm{hr}$.

\subsection{Flux sensitivity analysis}

For the last case let's assume that we decide to improve the flux without changing the feed bulk temperature or increasing the vacuum pressure at the permeate side. One may suggest replacing the membrane with another one that has higher mass transfer permeability. Another way may suggest increasing the heat transfer coefficient. Both of these actions are valid but which one of them is more effective in increasing the flux than the other. Bandini et al. [5] tried to answer this question by studying the sensitivity of the VMD flux to the changes in $C_{m}$ and $h$. In that study they introduced two new dimensionless sensitivity factors:

$$
\begin{gathered}
\varnothing_{m}=\frac{\frac{d J}{J}}{\frac{d C_{m}}{C_{m}}} \\
\varnothing_{h}=\frac{\frac{d J}{d h}}{\frac{d h}{h}}
\end{gathered}
$$

where $\phi_{\mathrm{m}}$ is the normalized sensitivity factor of the change in flux to the change in membrane mass transfer coefficient while $\phi_{\mathrm{h}}$ is the normalized sensitivity factor of the change in flux to the change in heat transfer coefficient. $\phi_{\mathrm{m}}$ is equal to one if any normalized change in $\mathrm{C}_{\mathrm{m}}$ introduces 
similar change in the normalized flux. $\phi_{m}$ will be equal to zero if a change in $C_{m}$ induces zero change in the normalized flux. The same thing can be said for the $\phi_{\mathrm{h}}$ factor. Based on equation 7 , the Bandini et al. [6] sensitivity analysis concluded that the two factors can be written as follow [6]:

$\varnothing_{m}=\frac{1}{1+R_{1}}$

$\varnothing_{h}=1-\varnothing_{m}$

$R_{1}=\frac{C_{m} g_{v}}{h} \frac{d P_{i}}{d T_{i}}$

The $\phi_{m}$ equation above shows that the sensitivity of the flux to $C_{m}$ increases as $R_{1}$ value approaches zero. The opposite is true for $\phi_{h}$. From Eq. (11) one can see that $R_{1}$ increases as $T_{i}$ increases because $\mathrm{dp}_{\mathrm{i}} / \mathrm{dT}_{\mathrm{i}}$ increases as $\mathrm{T}_{\mathrm{i}}$ increases according to Claus-Clapeyron equation [1]: $\left.\frac{d P}{d T}\right|_{\text {avg }}=\left.\frac{P_{a v g} g_{v} M}{R T_{\text {avg }}{ }^{2}}\right|_{\text {avg }}$

The value of $\mathrm{dP}_{\mathrm{i}} / \mathrm{dT}_{\mathrm{i}}$ spans a range of $144-1920 \mathrm{~Pa} / \mathrm{K}$ for $\mathrm{T}_{\mathrm{i}}$ temperature range of $80-20^{\circ} \mathrm{C}$. Additionally, $R_{1}$ is a function of $\mathrm{C}_{\mathrm{m}} \mathrm{g}_{\mathrm{v}} / \mathrm{h}$ which is the ratio of heat transfer rate by evaporation to the heat transfer rate by convection. In their evaluation to dpi/dTi of Eq. (11), Bandini et al. [6] assumed that $T_{i}$ is equal $T_{b}$ which we would expect introduces appreciable error to their analysis. A more accurate evaluation to $d p_{i} / d T_{i}$ should be achieved if it was evaluated after solving the mathematical equations of the VMD model.

Similar flux sensitivity analysis for $\mathrm{T}_{\mathrm{b}}$ and $\mathrm{P}_{\mathrm{v}}$ has been conducted by Banat et al. [23] where they introduced another two new normalized sensitivity factors:

$$
\begin{gathered}
\phi_{T_{b}}=\frac{\varnothing_{h}}{R_{2}} \\
\phi_{P_{v}}=\frac{-\varnothing_{m}}{R_{3}} \\
R_{2}=1-\frac{T_{i}}{T_{b}}
\end{gathered}
$$


$R_{3}=\frac{P_{i}}{P_{v}}-1$

Since $0 \leq \mathrm{R}_{2} \leq 1$ and $-1 \leq \mathrm{R}_{3} \leq 0$ then one can conclude that the sensitivity of the flux to the changes in $\mathrm{T}_{\mathrm{b}}$ and $\mathrm{P}_{\mathrm{v}}\left(\phi_{\mathrm{Tb}}\right.$ and $\phi_{\mathrm{Pv}}$ respectively) are always greater than that of $\phi_{\mathrm{h}}$ and $\phi_{\mathrm{m}}$, respectively.

\subsection{Temperature Polarization Coefficient (TPC)}

Temperature polarization coefficient (TPC) was defined by Schofield et al [1] for a DCMD configuration as the ratio of $\Delta \mathrm{T}$ at the membrane interface to the $\Delta \mathrm{T}$ of the bulk temperatures according to the following equation:

$T P C=\frac{T_{i f}-T_{i p}}{T_{b f}-T_{b p}}$

where $T_{\text {if }}$ and $T_{\text {ip }}$ are the temperatures of the feed and permeate fluids at the membrane interface, respectively, and $T_{b f}$ and $T_{b p}$ are the bulk temperatures of the feed and permeate, respectively.

This definition has been introduced to quantify the limitation created by the convective heat transfer coefficient on the DCMD flux. When TPC approaches a value of one, it signifies that the convective heat transfer coefficients are high and the bulk temperatures can be used in calculating the water vapor flux without significant error. As TPC approaches a value of zero, it tells us that the water vapor flux is limited by the heat transfer coefficients and the temperature at the membrane interface must be considered. A thorough search in the DCMD literature showed that no other definition than this has been reported for TPC of DCMD. On the contrary, three different TPC definitions for the VMD configuration have been used by different authors. Some authors $[35,55-57]$ defined the TPC of the VMD according to the following equation:

$T P C=\frac{T_{i}}{T_{b}}$

It seems that this definition was taken by analogy from the concentration polarization coefficient definition. Since the analogy between TPC and the concentration polarization coefficient is not perfect, we found this definition to be unsuitable. The TPC value in this definition approaches zero only when $T_{i}$ approaches zero which is not necessarily the case. In fact, TPC approaches zero when $T_{i}$ approaches the saturation temperature of the permeate 
pressure $\left(T_{v}\right)$ whether the value of $T_{v}$ is zero or any other temperature. Thus, this definition does not represent all possible cases of the VMD process.

Bandini et al. [6] defined the TPC of the VMD process as:

$T P C=\frac{T_{b}-T_{i}}{T_{b}-T_{v}}(19)$

In this definition, TPC approaches a value of zero when the heat transfer coefficient is high and approaches a value of one when the heat transfer coefficient is low. The value of this definition is the opposite of the TPC value in DCMD. It is most likely that Bandini et al. [6] defined the TPC of the VMD in such a way to make it consistent with the sensitivity factors that they introduced for the VMD process. We believe that standardizing the TPC value among all MD configurations is very important and is expected to eliminate any possible future confusion in the MD literature. Therefore, we suggest setting the value of the TPC defined for the DCMD configuration as the standard value for the other configurations. This means that TPC value approaches one when the heat transfer coefficient is high and it approaches zero when the heat transfer coefficient is low.

Some authors [52, 58] modified the Bandini et al. [6] definition and made its value agree with that of the TPC of the DCMD:

$T P C=\frac{T_{i}-T_{v}}{T_{b}-T_{v}}(20)$

They reached this new definition by simply subtracting the Bandini et al. [6] TPC equation from a value of 1 :

$$
T P C=1-\frac{T_{b}-T_{i}}{T_{b}-T_{v}}
$$

It is worth mentioning that the definition of Eq. (20) is not valid as the value of $T_{v}$ approaches the value of $T_{i}$ because as $T_{v}$ approaches $T_{i}$ then the value of $T_{v}$ will also approach $T_{b}$ which means that both the values of the numerator and denominator will approach zero (undefined case). However, in our opinion, we believe that this definition is the most appropriate one for the VMD configuration. Therefore, it is used to calculate the temperature polarization coefficient predicted by the developed mathematical model. 


\subsection{VMD mathematical modeling}

Developing a mathematical model for the heat and mass transport in VMD is relatively much simpler than those of the DCMD and AGMD configurations. With equation 6 and an iteration loop for $\mathrm{T}_{\mathrm{i}}$ we were able to develop a VMD mathematical model according to the following algorithm (Fig. 4):

Figure 4: VMD model algorithm.

This model was validated experimentally (see experiment section) and then it was used in analyzing the TPC and sensitivity factors for different operating conditions scenarios. A detailed comparison between these two has been conducted as well.

\section{Experimental}

A poly tetra fluoro ethylene (PTFE) flat sheet membrane provided by Sterlitech Corporation, USA, with a nominal pore size of $0.2 \mu \mathrm{m}$ was used in this study. Membrane samples were characterized for their morphology using Scanning Electron Microscopy (SEM), thickness, water contact angle, pore size, pore size distribution and porosity. A detailed membrane characterization procedure was described in previous work [54, 59]. The membrane characteristics and MD process performance for different configurations using real Red Seawater as feed solution showed that the used membrane could serve as one of the promising membranes among other commercially available and locally fabricated MD membranes $[53-55,60,61]$ at the same operating conditions. Membrane specimens of $5 \mathrm{~cm} \mathrm{x} 10 \mathrm{~cm}$ have been tested in a thermally insulated VMD flat sheet module made of poly methyl methacrylate, locally designed and fabricated. The channel height was $2 \mathrm{~mm}$ for both feed and permeates sides. The membrane module was mounted vertically in a bench scale set up. Water vapor (permeate) was condensed inside a $60 \mathrm{~cm}$ long glass coil immersed in an ice bath and collected in a sealed tank placed on an electronic Mettler Toledo balance (ML3002E Precision Balance, with readability of $0.01 \mathrm{~g}$ ). The permeate weight, pressure and temperature of the water vapor that comes out from the VMD module were monitored using in-line temperature and pressure sensors. The data were logged every 60 seconds via data acquisition software (Labview) to a computer hard drive. Deionized 
water at different flow rates ( 1 and $2 \mathrm{~L} / \mathrm{min})$ were used as a feed at three different temperatures $\left(60,70,80^{\circ} \mathrm{C}\right)$. The temperature of the feed was monitored via in-line Pt100 sensors inserted at the entrance of the membrane module to provide feedback signal to the heater controller. The vacuum is applied through a vacuum pump connected to the top of the permeate collection tank. The vacuum pressures at the initial time of all VMD runs were always lower than the saturation pressure of the hot feed. After reaching the maximum possible vacuum, the VMD setup was isolated to prevent any water vapor loss through the vacuum line. Even though the system was well isolated, the absolute pressure of the system was observed to increase slowly over time. The VMD process is considered as a semi-closed process and the accumulation of the water condensate inside the tank and maybe small air leaks are two possible causes for the increase of the absolute pressure of the system. A schematic diagram and a VMD experimental setup are shown in Figure 5.

Figure 5: A schematic diagram (left) and photo (right) of the VMD experimental setup.

\section{Results and discussion}

\subsection{Calculating the heat and mass transfer coefficients}

In the VMD mathematical model described in Section 2.3, the membrane mass transfer coefficient and the convective heat transfer coefficient are used as input parameters. However, calculating the values of these two coefficients from correlation equations reported in the literature gives, most of the time, unsatisfactory results which in turns affects the accuracy of the mathematical model. Therefore, we proposed to have these two coefficients as adjustable (fitting) parameters for tuning the mathematical model under one experimental run. The obtained coefficients have been then treated as constants and tested again under two more different experimental conditions to see how accurately the mathematical model predicts the results of the second and third experimental runs from the result of the first one. At first, the water vapor flux at different absolute permeate pressures $\left(\mathrm{P}_{\mathrm{v}}\right)$ for a constant feed temperature of $80{ }^{\circ} \mathrm{C}$ was measured. The data generated from this run showed a linear trend between the water vapor flux and the permeate pressure $\mathrm{P}_{\mathrm{v}}$ (Fig. 6). 
Figure 6: Water vapor flux vs. absolute permeate pressure $\left(\mathrm{T}_{b}=80^{\circ} \mathrm{C}\right.$, flow rate $\left.=2 \mathrm{~L} / \mathrm{min}\right)$.

The small noise in the flux was caused by the semi-batch transfer mode of the condensate to the tank placed on the balance. In order to match the experimental data, the mathematical model required the membrane mass transfer coefficient to be $0.0035 \mathrm{~kg} / \mathrm{m}^{2} . \mathrm{hr}$.Pa and the convective heat transfer coefficient to be $2.2 \mathrm{~kW} / \mathrm{m}^{2}$.C. Since these two coefficients are expected to remain constant, they were used in the model to predict the experimentally measured flux at different $\mathrm{P}_{\mathrm{v}}$ of feed temperatures of $70{ }^{\circ} \mathrm{C}$ and $60^{\circ} \mathrm{C}$. Figure 7 shows the experimental and predicted water vapor flux at these conditions.

Figure 7: Experimental and simulated water vapor flux vs. absolute permeate pressure at two different feed bulk temperatures, flow rate $=2 \mathrm{~L} / \mathrm{min}$ ).

The agreement between the mathematical model results and the experimental data was excellent, which gave us confidence in our mathematical model prediction. This model was used to compute and analyze the TPC and the flux sensitivity factors introduced by Bandini et al. [6].

\subsection{Temperature polarization coefficient and flux sensitivity factors}

\subsubsection{Temperature polarization coefficient (TPC)}

The developed mathematical model is considered as a useful tool for studying and analyzing the temperature polarization effect on VMD. Furthermore, it can give insight to what should be done to enhance the process flux under different scenarios of operating conditions and parameters. Figure 8 for instance represents one scenario of TPC behavior at different permeate pressures and constant feed temperature. It is clearly shown that the TPC decreases nonlinearly as the absolute pressure of $\mathrm{P}_{\mathrm{v}}$ increases. Such a result was not expected because we were expecting that as $P_{v}$ increases the flux decreases which in turns makes managing the heat supply from the bulk feed to the membrane interface through $\mathrm{h}$ much easier. However, what is shown in Figure 8 is the opposite (TPC decreases as $\mathrm{P}_{\mathrm{v}}$ increases).

Figure 8: TPC as a function of $\mathrm{P}_{\mathrm{v}}$ at feed temperature of $60{ }^{\circ} \mathrm{C}$ and flow rate of $2 \mathrm{~L} / \mathrm{min}$. 
Our mathematical analysis explaining this phenomenon showed that proofing or disproving the TPC decrease when $P_{v}$ increases for all values of $P_{v}$ is mathematically very complicated and requires further investigation. A deep explanation of this observed phenomenon will be reported in future work.

Another scenario is the behavior of TPC at constant $\mathrm{P}_{\mathrm{v}}$ and variant feed temperatures (Fig. 9).

Figure 9: Simulated TPC as a function of $\mathrm{T}_{\mathrm{b}}$ at permeate absolute pressure of $2 \mathrm{kPa}$ and feed flow rate of $2 \mathrm{~L} / \mathrm{min}$.

The modeling of this scenario was conducted at low absolute pressure $(2 \mathrm{kPa})$ in order to allow us to study TPC at lower feed temperatures. This relation is obvious and is expected because the increase of flux as a function of feed bulk temperature makes it difficult for $\mathrm{h}$ to supply the heat to the membrane interface without increasing the driving force of $\Delta \mathrm{T}$ which in turn reduces TPC. Unlike the relation of TPC with $\mathrm{P}_{\mathrm{v}}$, the TPC decreases linearly with $\mathrm{T}_{\mathrm{b}}$, as shown in Figure 9.

\subsubsection{Sensitivity factor of the flux to the heat transfer coefficient}

The definition of the sensitivity factor $\phi_{\mathrm{h}}$ is exactly the opposite of TPC. In other words, as $\mathrm{h}$ increases, $\phi_{\mathrm{h}}$ decreases to show less dependence on the heat transfer coefficient while TPC increases to show that there is no limitation created by the heat transfer coefficient. Such a conceptual difference in meaning in these two definitions prevents us from making a good comparison between them in the next section. Therefore, $\phi_{\mathrm{h}}$ was redefined to make its meaning similar to that of the TPC value. A careful look at Eqs. (7-11) would reveal that we can achieve our goal by simply replacing $\phi_{\mathrm{h}}$ with $\phi_{\mathrm{m}}$ and vice versa in that equation. In this way $\phi_{\mathrm{h}}$ has a value of one when the heat transfer is not limiting the process and a value of zero when the process is heat transfer limited. In order to distinguish this new definition from that of Bandini et al. [6], we are going to refer it as $\phi_{\mathrm{h}}{ }^{*}$.

$$
\varnothing_{h}{ }^{*}=1-\varnothing_{h}
$$


As is shown in Figure 10, the sensitivity factor $\phi_{\mathrm{h}}{ }^{*}$ decreases as $\mathrm{P}_{\mathrm{v}}$ increases. This implies the importance of improving $\mathrm{h}$, increasing as $\mathrm{P}_{\mathrm{v}}$ increases. This relation is in good agreement with the TPC analysis.

Figure 10: Simulated $\phi_{\mathrm{h}}{ }^{*}$ as a function of $\mathrm{P}_{\mathrm{v}}$ at feed temperature of $60{ }^{\circ} \mathrm{C}$ and flow rate of 2 $\mathrm{L} / \mathrm{min}$.

The $\phi_{\mathrm{h}}{ }^{*}$ scenario at constant $\mathrm{P}_{\mathrm{v}}$ and variable $\mathrm{T}_{\mathrm{b}}$ is presented in Figure 11. As $\mathrm{T}_{\mathrm{b}}$ increases, $\phi_{\mathrm{h}} *$ decreases, which again agrees with the TPC trend.

Figure 11: Simulated $\phi_{\mathrm{h}}{ }^{*}$ as a function of $\mathrm{T}_{\mathrm{b}}$ at permeate absolute pressure of $2 \mathrm{kPa}$ and feed flow rate of $2 \mathrm{~L} / \mathrm{min}$.

\subsubsection{Comparison between TPC and the sensitivity factor of flux to heat transfer coefficient}

It was shown in the last section that both $\phi_{\mathrm{h}}{ }^{*}$ and TPC gave similar indications of the effect of temperature polarization at different operating conditions scenarios. But here we would like to analyze how their values differ from each other and which one of them is expected to give a more accurate indication about temperature polarization than the other. Figures 12 and 13 show a comparison between TPC and $\phi_{\mathrm{h}}{ }^{*}$ under two different operating condition scenarios.

Figure 12: Simulated comparison between TPC and $\phi_{\mathrm{h}}{ }^{*}\left(\mathrm{~T}_{\mathrm{b}}=80^{\circ} \mathrm{C}\right)$

Figure 13: Simulated comparison between TPC and $\phi_{\mathrm{h}} *\left(\mathrm{P}_{\mathrm{v}}=2 \mathrm{kPa}\right)$

In both graphs $\phi_{h} *$ is always lower or equal to the TPC value. The difference at constant $T_{b}$ and variable $\mathrm{P}_{\mathrm{v}}$ is as high as $6 \%$ at $15 \mathrm{kPa}$ while the difference reached $20 \%$ in the second scenario at $\mathrm{T}_{\mathrm{b}}$ of $80^{\circ} \mathrm{C}$. It might be difficult to decide which one of these measures is more convenient for quantifying the temperature polarization. But, if we combine Eqs (9-11) and Eq. (22), we get: 
$\varnothing_{h}^{*}=\frac{1}{1+\frac{C_{m} g_{v}}{h} \frac{d P_{i}}{d T_{i}}}$

Therefore, the heat transfer sensitivity factor might be more convenient than TPC for measuring temperature polarization for the following reasons:

1- Heat transfer sensitivity coefficient shows how temperature polarization is related to the membrane permeability and heat transfer coefficient while TPC does not.

2- Heat transfer sensitivity coefficient shows how temperature polarization changes as feed temperature changes by looking at the slope $d p_{i} / d T_{i}$ of the vapor pressure saturation curve.

\subsubsection{Temperature polarization and process scale-up}

In previous works $[53,54]$ we highlighted that all thermal separation processes are thermally inefficient unless the thermal energy utilized in the phase change is recycled back to the process through a heat recovery system. So, if a heat recovery system is integrated into a VMD process (Fig. 14) then the latter will have a similar design to that of the AGMD configuration except that the vapor condensation will take place outside the membrane module and the process will be operating under vacuum instead of atmospheric pressure.

Figure14: Process flow diagram of a heat recovery system integrated to a VMD process.

Therefore, it is expected that the compact VMD module design that allows running the process under vacuum pressure will be one of the most attractive potential designs for scaling up the MD technology. Such a design will be discussed in more detail in another paper. But here, the discussion will be limited to how the integration of a heat recovery system would change the temperature polarization effect on VMD water vapor flux.

As shown in Figure 14, the feed water is used as coolant medium for the water vapor condenser where it recovers the latent heat from the vapor. The increase of the feed temperature during its flow through the condenser reduces the water vapor condensation rate and causes the non-condensed vapor to exit the process through the vacuum system. To rectify such a problem, the absolute pressure inside the VMD module and the condenser must be increased to a point 
where the pressure is higher than the saturation pressure of the feed water temperature that passes through the condenser tubes and lower than the saturation pressure of $\mathrm{T}_{\mathrm{i}}$ to sustain some water vapor generation. If the same operational procedure used in the conventional thermal separation processes such as Multi-Stage Flash (MSF), for example, is applied then the absolute pressure inside the stage is set at the saturation pressure of the evaporating surface temperature. Inside the condenser, the MSF feed water temperature is usually lower than the evaporation surface temperature by $5-7^{\circ} \mathrm{C}$. This temperature difference is low enough to condense the vapor. However, such pressure cannot be applied for the VMD process because in the MSF there is no mass transfer resistance between the evaporation and condensation surfaces except for the small one caused by the demister pad at the top of the distiller while the VMD process has considerable mass transfer resistance caused by the membrane pores structure. The membrane mass transfer resistance necessitates setting the absolute pressure of the permeate side of the VMD module and its condenser at a pressure corresponding to a saturation temperature that is somewhere between $T_{i}$ and the temperature of the feed that passes through the condenser. Such a pressure will assure continual generation of water vapor and cause that vapor to condense inside the condenser. In brief, integrating a heat recovery system to a VMD module enhances the thermal efficiency of the process but necessitates operating the VMD under $\mathrm{P}_{\mathrm{v}}$ pressure close to the saturation pressure of $\mathrm{T}_{\mathrm{i}}$ and our objective is to study how such conditions affect the TPC value.

Figure 15: The effect of $\left(\mathrm{T}_{\mathrm{i}}-\mathrm{T}_{\mathrm{sat}}\right)$ on TPC as a function of feed bulk temperature.

As it is shown in Figure 15, the TPC value is as low as 0.39 at $\mathrm{T}_{\mathrm{b}}$ of $80{ }^{\circ} \mathrm{C}$. These conditions correspond to $3.5^{\circ} \mathrm{C}$ temperature difference between $T_{i}$ and the saturation temperature of $\mathrm{P}_{\mathrm{v}}$ $\left(\mathrm{T}_{\text {sat }}\right)$. The graph also shows the TPC values at different $\mathrm{T}_{\mathrm{b}}$ temperatures for two more temperature differences $\left(5\right.$ and $\left.7^{\circ} \mathrm{C}\right)$. In most of the bench scale experiments, the VMD is run at low $\mathrm{P}_{\mathrm{v}}$ and high $\mathrm{T}_{\mathrm{b}}$. These conditions correspond to high temperature difference between $\mathrm{T}_{\mathrm{i}}$ and $\mathrm{T}_{\text {sat }}$ which gives relatively higher TPC values than those (large modules) at conditions where the heat recovery is integrated to the VMD process. The dotted curve in Figure 15 shows that TPC is much higher at the bench scale test conditions than at the conditions where heat recovery system 
is integrated to the process. The reason for the low TPC values with heat recovery system is the combined effect that we discussed in Figures 8 and 9.

\section{Conclusions}

The work reported in this paper focused on studying the temperature polarization effect on water vapor flux in VMD. The outcomes of this study can be summarized as follow:

- The VMD configuration was found to be much simpler and more suitable for the study of temperature polarization than the DCMD configuration.

- The development of a VMD mathematical model is relatively simpler than that of the other MD configurations and accurate prediction was achieved when the heat transfer coefficient and membrane mass transfer coefficient were used as adjustable parameters for validation with the experimental data.

- The flux sensitivity factor to membrane mass transfer resistance and TPC were found to decrease as $\mathrm{T}_{\mathrm{b}}$ increases.

- The sensitivity factor of the flux to membrane mass transfer resistance and TPC were found to decrease as the absolute pressure of the permeate side increases.

- The integration of a heat recovery system into a VMD module necessitates operating the module and its condenser at absolute pressure slightly below the saturation pressure of the feed temperature at the membrane interface. Under these conditions, the effect of temperature polarization was expected to be worse than the bench scale conditions where the absolute pressure at the permeate side is much lower than the saturation pressure of the feed temperature at the membrane interface. 


\section{Nomenclature}

$\mathrm{C}_{\mathrm{m}} \quad: \quad$ membrane mass transfer coefficient $\left(\mathrm{kg} \cdot \mathrm{m}^{-2} \cdot \mathrm{s}^{-1} \cdot \mathrm{Pa}^{-1}\right)$

$\mathrm{g}_{\mathrm{v}} \quad: \quad$ saturated water vapor enthalpy $\left(\mathrm{kJ}^{\mathrm{kg}} \mathrm{kg}^{-1}\right)$

$\mathrm{h} \quad: \quad$ convective heat transfer coefficient $\left(\mathrm{kJ} \cdot \mathrm{m}^{-2} \cdot \mathrm{s}^{-1} \cdot \mathrm{C}^{-1}\right)$

$\mathrm{J} \quad$ : $\quad$ water vapor flux (kg.m $\left.2 \cdot \mathrm{s}^{-1}\right)$

$\mathrm{J}_{\mathrm{k}} \quad$ : Knudsen diffusion flux $\left(\mathrm{kg} \cdot \mathrm{m}^{-2} \cdot \mathrm{s}^{-1}\right)$

$\mathrm{J}_{\mathrm{p}} \quad$ : $\quad$ Poiseuille's flow regime flux $\left(\mathrm{kg} \cdot \mathrm{m}^{-2} 2 \mathrm{~s}^{-1}\right)$

M : molecular weight of water (kg.mole ${ }^{-1}$ )

$\mathrm{P}_{\mathrm{i}} \quad$ : water vapor pressure at the feed-membrane interface $(\mathrm{Pa})$

$\mathrm{P}_{\mathrm{v}} \quad$ : $\quad$ water vapor pressure at the permeate side of the membrane $(\mathrm{Pa})$

$\mathrm{P}_{\text {avg }}: \quad$ average water vapor pressure $(\mathrm{Pa})$

$\Delta \mathrm{P} \quad$ : $\quad$ water vapor pressure difference across the membrane $(\mathrm{Pa})$

$\mathrm{Q} \quad$ : heat flux $\left(\mathrm{KJ} \cdot \mathrm{m}^{-2} \cdot \mathrm{s}^{-1}\right)$

$\mathrm{r} \quad$ : average membrane pore diameter $(\mathrm{m})$

$\mathrm{R} \quad$ : universal gas constant $\left(8.314 \mathrm{~m}^{3} \cdot \mathrm{Pa} \cdot \mathrm{K}^{-1} \cdot \mathrm{mole}^{-1}\right)$

$\mathrm{R}_{1} \quad$ : defined by Eq. (11)

$\mathrm{R}_{2} \quad$ : defined by Eq. (15)

$\mathrm{R}_{3} \quad$ : defined by Eq. (16)

$\mathrm{T}_{\text {avg }}$ : $\quad$ average absolute temperature inside membrane pores $(\mathrm{K})$

$\mathrm{T}_{\mathrm{b}} \quad$ : feed bulk temperature in $\operatorname{VMD}\left({ }^{\circ} \mathrm{C}\right)$

$\mathrm{T}_{\mathrm{bf}} \quad: \quad$ feed bulk temperature in DCMD $\left({ }^{\circ} \mathrm{C}\right)$

$\mathrm{T}_{\mathrm{bp}}$ : permeate bulk temperature in DCMD $\left({ }^{\circ} \mathrm{C}\right)$

$\mathrm{T}_{\mathrm{i}}$ : feed temperature at the membrane interface in $\operatorname{VMD}\left({ }^{\circ} \mathrm{C}\right)$

$\mathrm{T}_{\text {if }} \quad: \quad$ feed temperature at the membrane interface in DCMD $\left({ }^{\circ} \mathrm{C}\right)$

$\mathrm{T}_{\text {ip }}:$ permeate temperature at the membrane interface in DCMD $\left({ }^{\circ} \mathrm{C}\right)$

TPC : Temperature Polarization Coefficient

$\delta \quad: \quad$ membrane thickness $(\mathrm{m})$

$\varepsilon \quad: \quad$ membrane porosity

$\eta \quad: \quad$ water vapor viscosity (Pa.s) 
$\eta \quad: \quad$ water vapor viscosity (Pa.s)

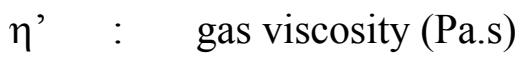

$v \quad: \quad$ mean molecular speed of the water molecule $\left(\mathrm{m} \cdot \mathrm{s}^{-1}\right)$

$\zeta \quad$ : Poiseuille's flow regime contribution ratio relative Knudsen flow.

$\tau$ : membrane tortuosity

$\phi_{\mathrm{h}} \quad$ : flux sensitivity to the convective heat transfer coefficient factor

$\phi_{\mathrm{m}} \quad$ : flux sensitivity to the membrane mass transfer coefficient factor

$\phi_{\mathrm{pv}} \quad$ : flux sensitivity to permeate vacuum pressure factor

$\phi_{\mathrm{Tb}} \quad$ : flux sensitivity to feed bulk temperature factor 


\section{References}

[1] R.W. Schofield, A.G. Fane, C.J.D. Fell, Heat and Mass-Transfer in Membrane Distillation, J Membrane Sci 33 (1987) 299-313.

[2] L. Camacho, L. Dumée, J. Zhang, J.-d. Li, M. Duke, J. Gomez, S. Gray, Advances in Membrane Distillation for Water Desalination and Purification Applications, Water 5 (2013) 94-196.

[3] A.G. Fane, R.W. Schofield, C.J.D. Fell, The Efficient Use of Energy in Membrane Distillation, Desalination 64 (1987) 231-243.

[4] V. Calabro, E. Drioli, Polarization phenomena in integrated reverse osmosis and membrane distillation for seawater desalination and waste water treatment, Desalination 108 (1997) 81-82.

[5] L. Martinez-Diez, M.I. Vazquez-Gonzalez, Temperature and concentration polarization in membrane distillation of aqueous salt solutions, J Membrane Sci 156 (1999) 265-273.

[6] S. Bandini, C. Gostoli, G.C. Sarti, Separation Efficiency in Vacuum Membrane Distillation, J Membrane Sci 73 (1992) 217-229.

[7] L. Martinez-Diez, M.I. Vazquez-Gonzalez, F.J. Florido-Diaz, Study of membrane distillation using channel spacers, J Membrane Sci 144 (1998) 45-56.

[8] L. Martinez-Diez, M.I. Vazquez-Gonzalez, F.J. Florido-Diaz, Temperature polarization coefficients in membrane distillation, Separ Sci Technol 33 (1998) 787-799.

[9] J.M. Rodriguez-Maroto, L. Martinez, Bulk and measured temperatures in direct contact membrane distillation, J Membrane Sci 250 (2005) 141-149.

[10] L. Martinez, J.M. Rodriguez-Maroto, On transport resistances in direct contact membrane distillation, J Membrane Sci 295 (2007) 28-39.

[11] H. Yu, X. Yang, R. Wang, A.G. Fane, Analysis of heat and mass transfer by CFD for performance enhancement in direct contact membrane distillation, J Membrane Sci 405406 (2012) 38-47.

[12] X. Yang, H. Yu, R. Wang, A.G. Fane, Analysis of the effect of turbulence promoters in hollow fiber membrane distillation modules by computational fluid dynamic (CFD) simulations, J Membrane Sci 415-416 (2012) 758-769. 
[13] Z. Xu, Y. Pan, Y. Yu, CFD simulation on membrane distillation of $\mathrm{NaCl}$ solution, in: Frontiers of Chemical Engineering in China, Springer (2009), pp. 293-297.

[14] M. Shakaib, S.M.F. Hasani, M. Ehtesham-ul Haque, I. Ahmed, R.M. Yunus, A CFD study of heat transfer through spacer channels of membrane distillation modules, Desalin Water Treat 51 (2013) 3662-3674.

[15] M. Shakaib, S.M.F. Hasani, I. Ahmed, R.M. Yunus, A CFD study on the effect of spacer orientation on temperature polarization in membrane distillation modules, Desalination 284 (2012) 332-340.

[16] A. Cipollina, G. Micale, L. Rizzuti, Membrane distillation heat transfer enhancement by CFD analysis of internal module geometry, Desalin Water Treat 25 (2011) 195-209.

[17] A. Cipollina, A. Di Miceli, J. Koschikowski, G. Micale, L. Rizzuti, CFD simulation of a membrane distillation module channel, Desalin Water Treat 6 (2009) 177-183.

[18] S. Al-Sharif, M. Albeirutty, A. Cipollina, G. Micale, Modelling flow and heat transfer in spacer-filled membrane distillation channels using open source CFD code, Desalination 311 (2013) 103-112.

[19] X. Yang, H. Yu, R. Wang, A.G. Fane, Optimization of microstructured hollow fiber design for membrane distillation applications using CFD modeling, J Membrane Sci 421-422 (2012) 258-270.

[20] K. Sakai, T. Koyano, T. Muroi, M. Tamura, Effects of Temperature and Concentration Polarization on Water-Vapor Permeability for Blood in Membrane Distillation, Chem Eng J Bioch Eng 38 (1988) B33-B39.

[21] A. Ali, F. Macedonio, E. Drioli, S. Aljlil, O.A. Alharbi, Experimental and theoretical evaluation of temperature polarization phenomenon in direct contact membrane distillation, Chem Eng Reses Des 91 (2013) 1966-1977.

[22] M. Khayet, T. Matsuura, Membrane distillation: principles and applications, Access Online via Elsevier, 2011.

[23] F.A. Banat, J. Simandl, Removal of benzene traces from contaminated water by vacuum membrane distillation, Chem Eng Sci 51 (1996) 1257-1265.

[24] N. Couffin, C. Cabassud, V. Lahoussine-Turcaud, A new process to remove halogenated VOCs for drinking water production: vacuum membrane distillation, Desalination 117 (1998) 233-245. 
[25] Z. Jin, D.L. Yang, S.H. Zhang, X.G. Ran, Removal of 2,4-dichlorophenol from wasterwater by vacuum membrane distillation using hydrophobic PPESK hollow hiber membrane, Chinese Chem Lett 18 (2007) 1543-1547.

[26] G.C. Sarti, C. Gostoli, S. Bandini, Extraction of Organic-Components from Aqueous Streams by Vacuum Membrane Distillation, J Membrane Sci 80 (1993) 21-33.

[27] J.J. Tang, K.G. Zhou, Q.X. Zhang, Q.G. Li, Study on the removal of MIBK from aqueous solution by vacuum membrane distillation, J Cent South Univ T 7 (2000) 178-181.

[28] A.M. Urtiaga, E.D. Gorri, G. Ruiz, I. Ortiz, Parallelism and differences of pervaporation and vacuum membrane distillation in the removal of VOCs from aqueous streams, Sep Purif Technol 22-3 (2001) 327-337.

[29] A.M. Urtiaga, G. Ruiz, I. Ortiz, Kinetic analysis of the vacuum membrane distillation of chloroform from aqueous solutions, J Membrane Sci 165 (2000) 99-110.

[30] B. Wu, X.Y. Tan, K. Li, W.K. Teo, Removal of 1,1,1-trichloroethane from water using a polyvinylidene fluoride hollow fiber membrane module: Vacuum membrane distillation operation, Sep Purif Technol 52 (2006) 301-309.

[31] B. Wu, X.Y. Tan, W.K. Teo, K. Li, Removal of benzene/toluene from water by vacuum membrane distillation in a PVDF hollow fiber membrane module, Separ Sci Technol 40 (2005) 2679-2695.

[32] E. Hoffmann, D.M. Pfenning, E. Philippsen, P. Schwahn, M. Sieber, R. Wehn, D. Woermann, G. Wiedner, Evaporation of alcohol/water mixtures through hydrophobic porous membranes, J Membrane Sci 34 (1987) 199-206.

[33] N. Qureshi, M.M. Meagher, R.W. Hutkins, Recovery of 2,3-Butanediol by Vacuum Membrane Distillation, Separ Sci Technol 29 (1994) 1733-1748.

[34] Y. Xu, B.K. Zhu, Y.Y. Xu, Pilot test of vacuum membrane distillation for seawater desalination on a ship, Desalination 189 (2006) 165-169.

[35] J.P. Mericq, S. Laborie, C. Cabassud, Evaluation of systems coupling vacuum membrane distillation and solar energy for seawater desalination, Chem Eng J 166 (2011) 596-606.

[36] J.P. Mericq, S. Laborie, C. Cabassud, Vacuum membrane distillation of seawater reverse osmosis brines, Water Res 44 (2010) 5260-5273.

[37] J.P. Mericq, S. Laborie, C. Cabassud, Vacuum membrane distillation for an integrated seawater desalination process, Desalin Water Treat 9 (2009) 287-296. 
[38] B.L. Pangarkar, P.V. Thorat, S.B. Parjane, R.M. Abhang, Performance evaluation of vacuum membrane distillation for desalination by using a flat sheet membrane, Desalin Water Treat 21 (2010) 328-334.

[39] F.F. Shao, L. Ni, Y.F. Zhang, Y.B. Chen, Z. Liu, Z. Cao, Study on vacuum membrane distillation of PP hollow fiber membranes used in concentrated seawater from low-pressure reverse osmosis, Desalin Water Treat 51 (2013) 3925-3929.

[40] Y.L. Wu, Y.D. Wei, J.Z. Liu, J.P. Xu, An Experimental-Study on Membrane Distillation for Treatment of Ginseng Dew and Ginseng Washing Water, Chinese Sci Bull 34 (1989) 640-644.

[41] Z.P. Zhao, F.W. Ma, W.F. Liu, D.Z. Liu, Concentration of ginseng extracts aqueous solution by vacuum membrane distillation. 1. Effects of operating conditions, Desalination 234 (2008) 152-157.

[42] Z.P. Zhao, C.Y. Zhu, D.Z. Liu, W.F. Liu, Concentration of ginseng extracts aqueous solution by vacuum membrane distillation 2 . Theory analysis of critical operating conditions and experimental confirmation, Desalination 267 (2011) 147-153.

[43] R. Bagger-Jorgensen, A.S. Meyer, M. Pinelo, C. Varming, G. Jonsson, Recovery of volatile fruit juice aroma compounds by membrane technology: Sweeping gas versus vacuum membrane distillation, Innov Food Sci Emerg 12 (2011) 388-397.

[44] R. Bagger-Jorgensen, A.S. Meyer, C. Varming, G. Jonsson, Recovery of volatile aroma compounds from black currant juice by vacuum membrane distillation, J Food Eng 64 (2004) 23-31.

[45] N. Diban, O.C. Voinea, A. Urtiaga, I. Ortiz, Vacuum membrane distillation of the main pear aroma compound: Experimental study and mass transfer modeling, J Membrane Sci 326 (2009) 64-75.

[46] A. Hasanoglu, F. Rebolledo, A. Plaza, A. Torres, J. Romero, Effect of the operating variables on the extraction and recovery of aroma compounds in an osmotic distillation process coupled to a vacuum membrane distillation system, J Food Eng 111 (2012) 632641.

[47] H.T. Wang, B.A. Li, L. Wang, S.S. Song, J.X. Wang, Y.K. Feng, S.C. Wang, Permeate Flux Curve Characteristics Analysis of Cross-Flow Vacuum Membrane Distillation, Ind Eng Chem Res 51 (2012) 487-494. 
[48] F. Banat, F. Abu Al-Rub, K. Bani-Melhem, Desalination by vacuum membrane distillation: sensitivity analysis, Sep Purif Technol 33 (2003) 75-87.

[49] S. Bandini, G.C. Sarti, Heat and mass transport resistances in vacuum membrane distillation per drop, Aiche J, 45 (1999) 1422-1433.

[50] K.W. Lawson, D.R. Lloyd, Membrane distillation .1. Module design and performance evaluation using vacuum membrane distillation, J Membrane Sci 120 (1996) 111-121.

[51] J.H. Zhang, J.D. Li, M. Duke, M. Hoang, Z.L. Xie, A. Groth, C. Tun, S. Gray, Modelling of vacuum membrane distillation, J Membrane Sci 434 (2013) 1-9.

[52] S.G. Lovineh, M. Asghari, B. Rajaei, Numerical simulation and theoretical study on simultaneous effects of operating parameters in vacuum membrane distillation, Desalination 314 (2013) 59-66.

[53] A.S. Alsaadi, N. Ghaffour, J.D. Li, S. Gray, L. Francis, H. Maab, G.L. Amy, Modeling of air-gap membrane distillation process: A theoretical and experimental study, J Membrane Sci 445 (2013) 53-65.

[54] L. Francis, A.S. Alsaadi, N. Ghaffour, G.L. Amy, Performance evaluation of the DCMD desalination process under bench scale and large scale module operating conditions, $\mathrm{J}$ Membrane Sci 455 (2014) 103-112.

[55] B. Li, K.K. Sirkar, Novel membrane and device for direct contact membrane distillationbased desalination process, Ind Eng Chem Res 43 (2004) 5300-5309.

[56] F. Banat, S. Al-Asheh, M. Qtaishat, Treatment of waters colored with methylene blue dye by vacuum membrane distillation, Desalination 174 (2005) 87-96. 
[57] S. Al-Asheh, F. Banat, M. Qtaishat, M. Al-Khateeb, Concentration of sucrose solutions via vacuum membrane distillation, Desalination 195 (2006) 60-68.

[58] M. Khayet, T. Matsuura, Pervaporation and vacuum membrane distillation processes: Modeling and experiments, Aiche J 50 (2004) 1697-1712.

[59] L. Francis, N. Ghaffour, A. AlSaadi, S. Nunes, G. Amy, PVDF hollow fiber and nanofiber membranes for fresh water reclamation using membrane distillation, J Mater Sci 49 (2014) 2045-2053.

[60] H. Maab, A. Alsaadi, L. Francis, S. Livazovic, N. Ghaffour, G.L. Amy, S.P. Nunes, Polyazole hollow fiber membranes for direct contact membrane distillation, Industrial \& Engineering Chemistry Research 52 (2013) 10425-10429.

[61] L. Francis, N. Ghaffour, A. Alsaadi, G. Amy, Material gap membrane distillation: A new design for water vapor flux enhancement, J Membrane Sci 448 (2013) 240-247. 


\section{$\underline{\text { Highlights }}$}

- This work focused on studying the temperature polarization (TP) effect on flux in VMD

- Experimental data were used to validate the developed mathematical model

- Accurate prediction was achieved

- Flux sensitivity factors and TP Coefficient (TPC) are analyzed and compared

- The effect of TP was also studied for large scale modules having heat recovery system 


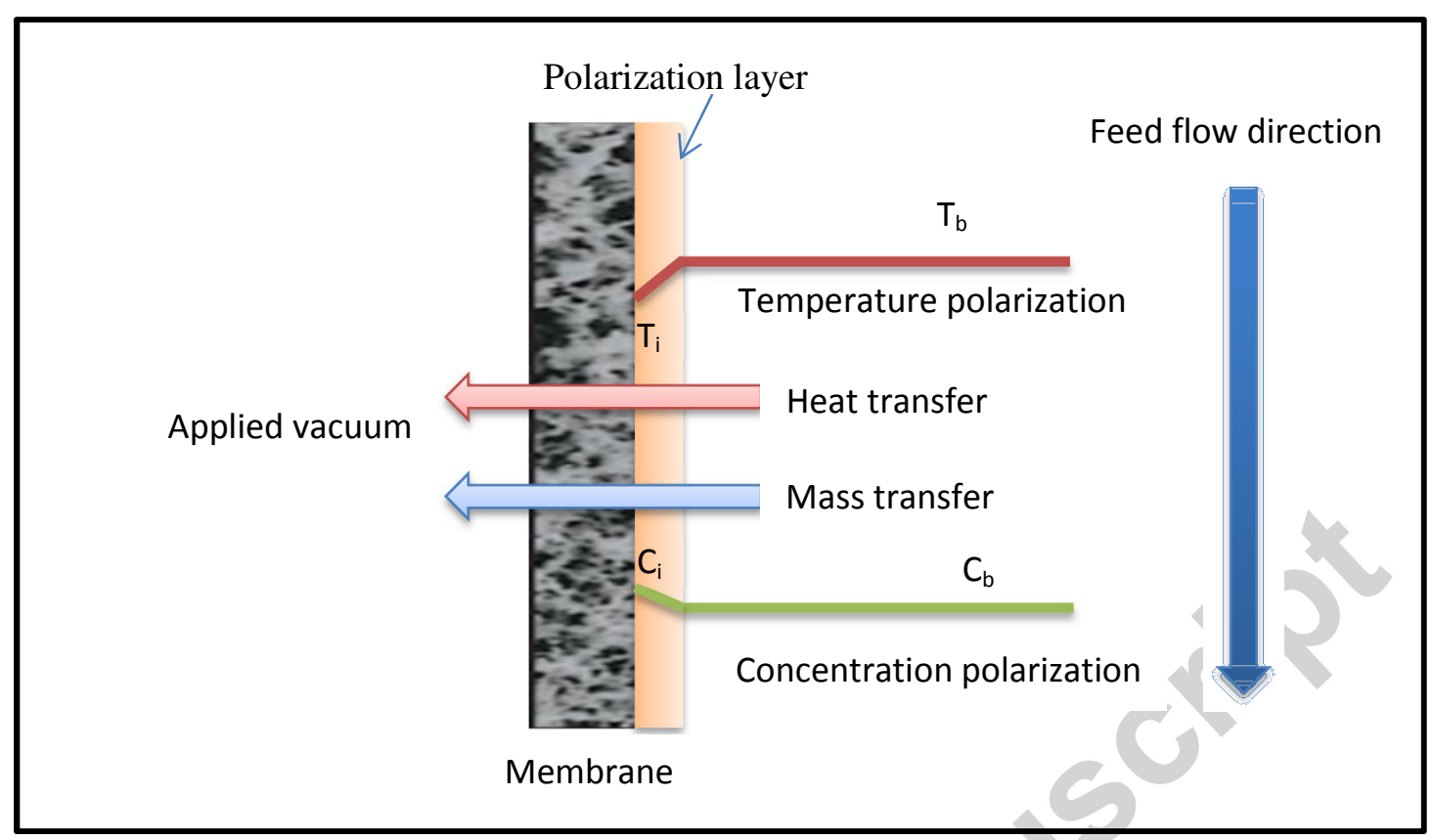

Figure 1: The two types of polarization phenomenon in membrane processes. 


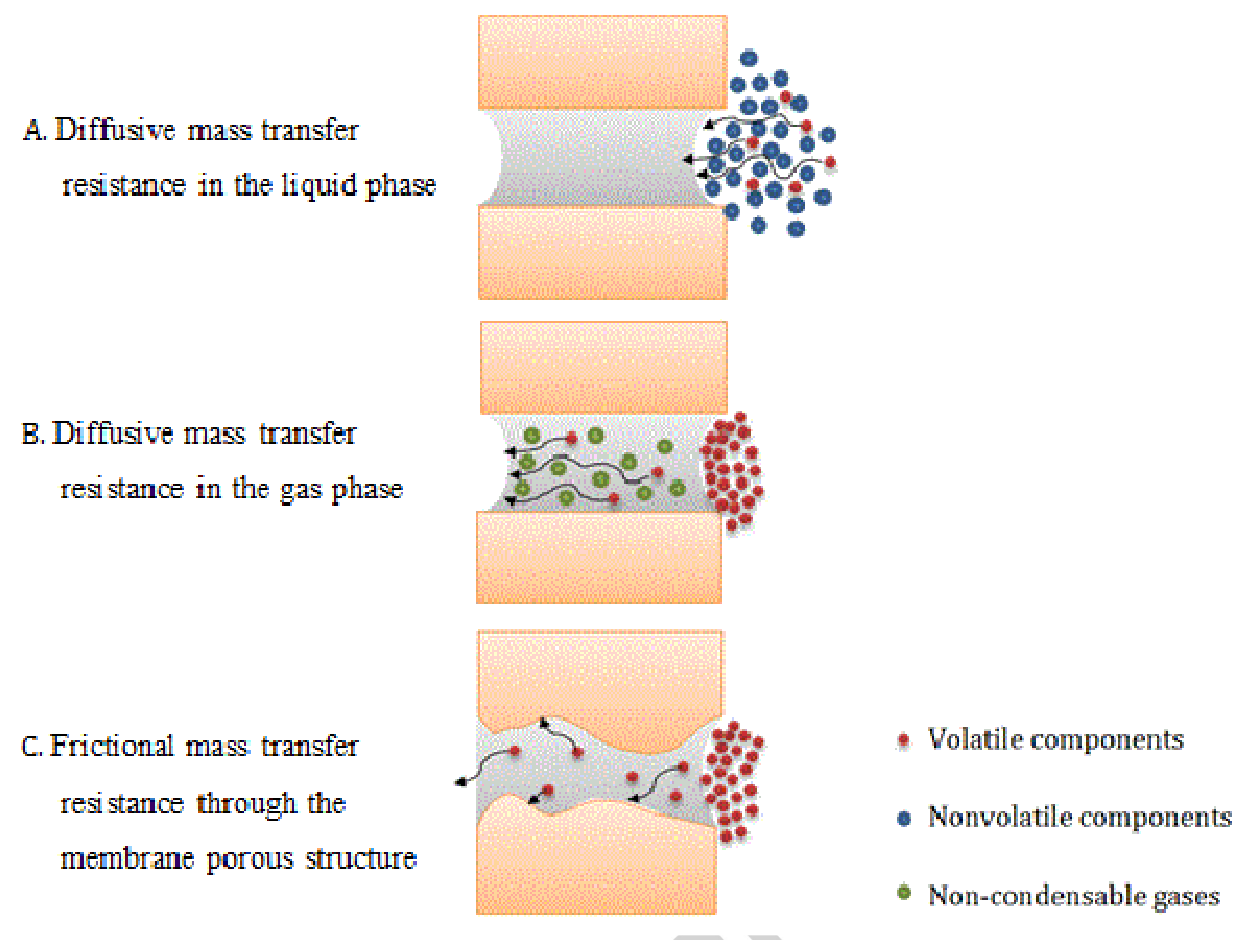

Figure 2: Diffusive mass transfer resistance in (A) the liquid phase, (B) the gas phase, and (C) frictional mass transfer resistance through the membrane pores in VMD process. 


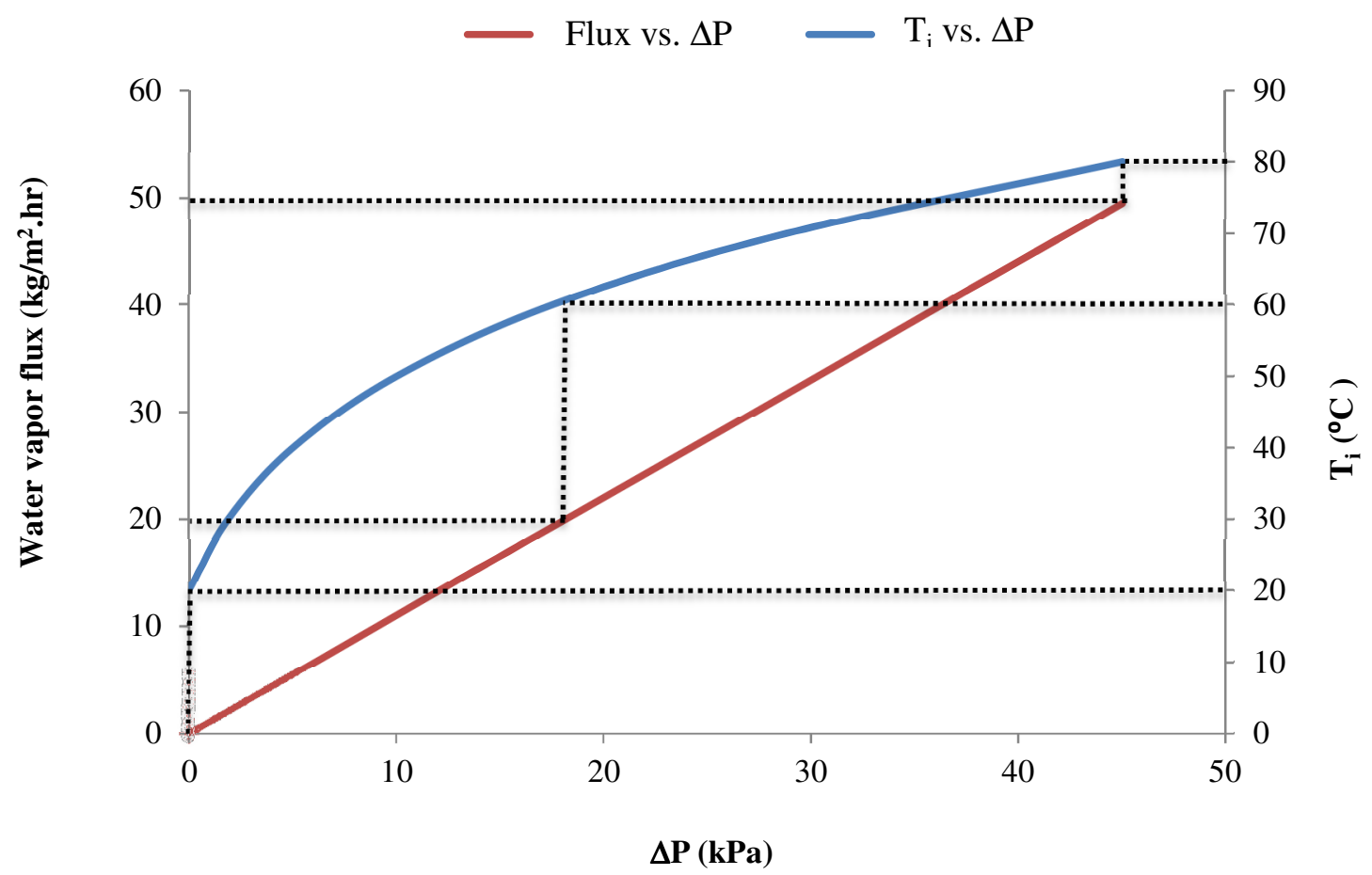

Figure 3: A graphical method for calculation of water vapor flux at different $T_{i}$. 


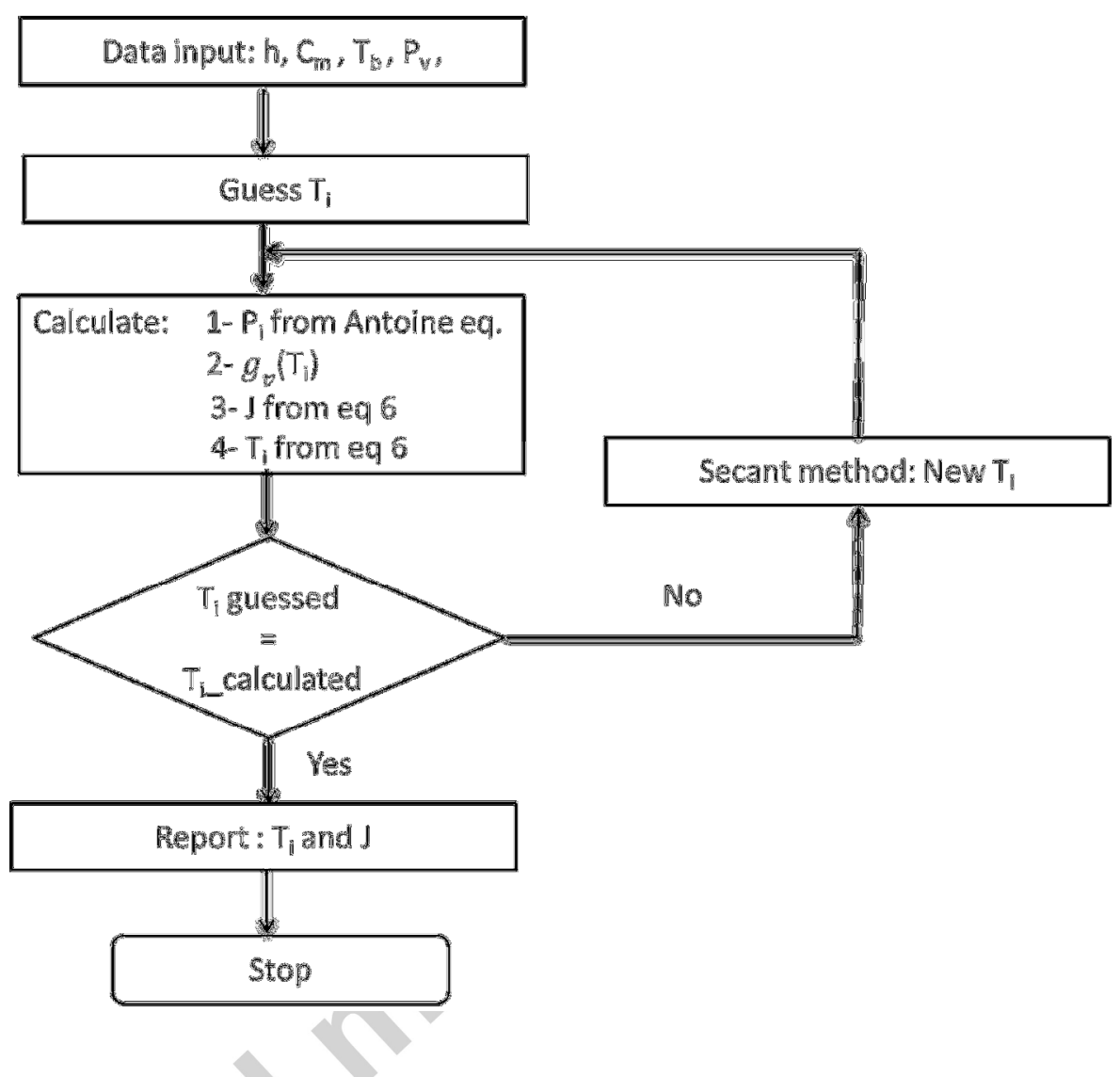

Figure 4: VMD model algorithm. 

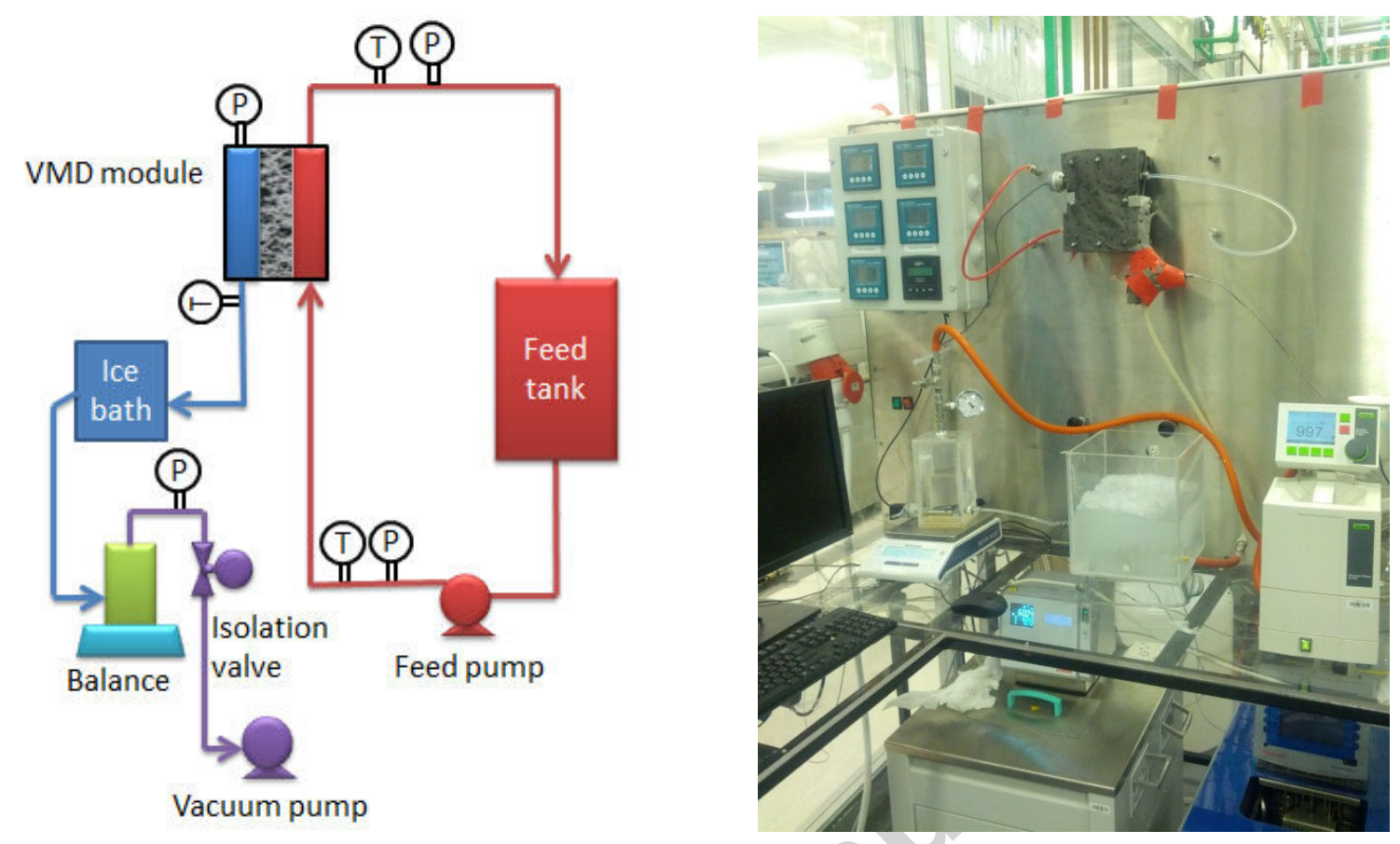

Figure 5: A schematic diagram (left) and photo (right) of the VMD experimental setup. 


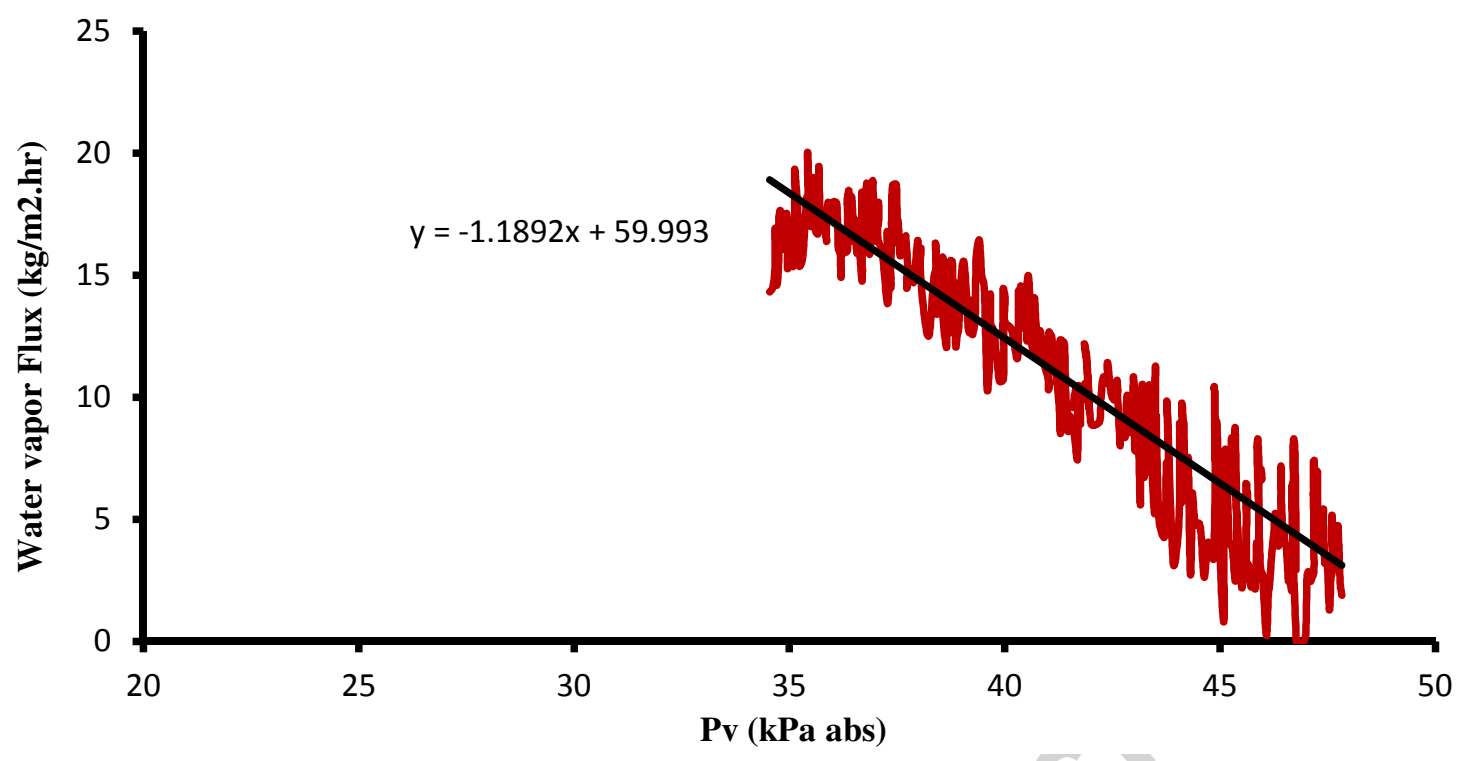

Figure 6: Water vapor flux vs. absolute permeate pressure $\left(\mathrm{T}_{\mathrm{b}}=80^{\circ} \mathrm{C}\right.$, flow rate $=$ $2 \mathrm{~L} / \mathrm{min})$. 


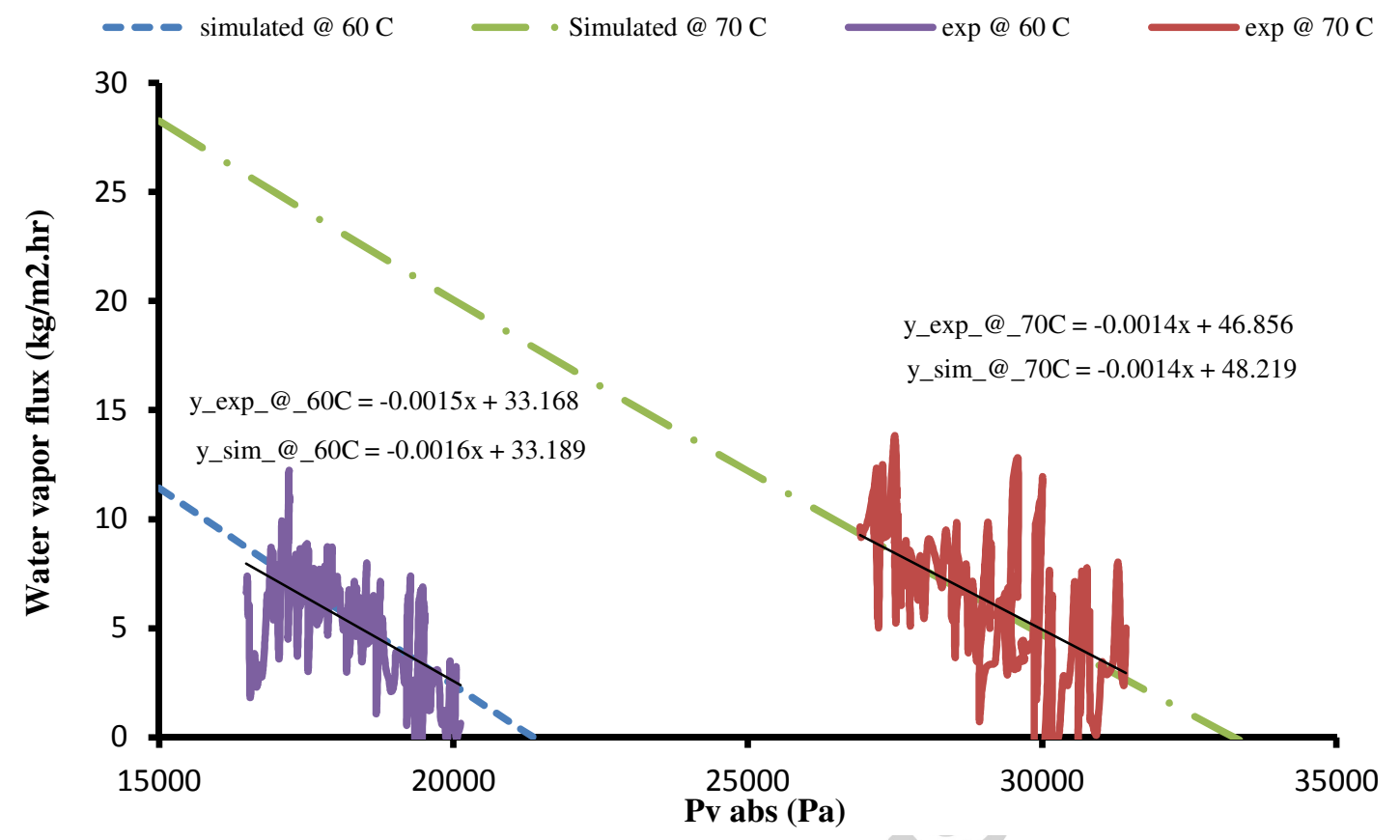

Figure 7: Experimental and simulated water vapor flux vs. absolute permeate pressure at two different feed bulk temperatures, flow rate $=2 \mathrm{~L} / \mathrm{min}$ ). 


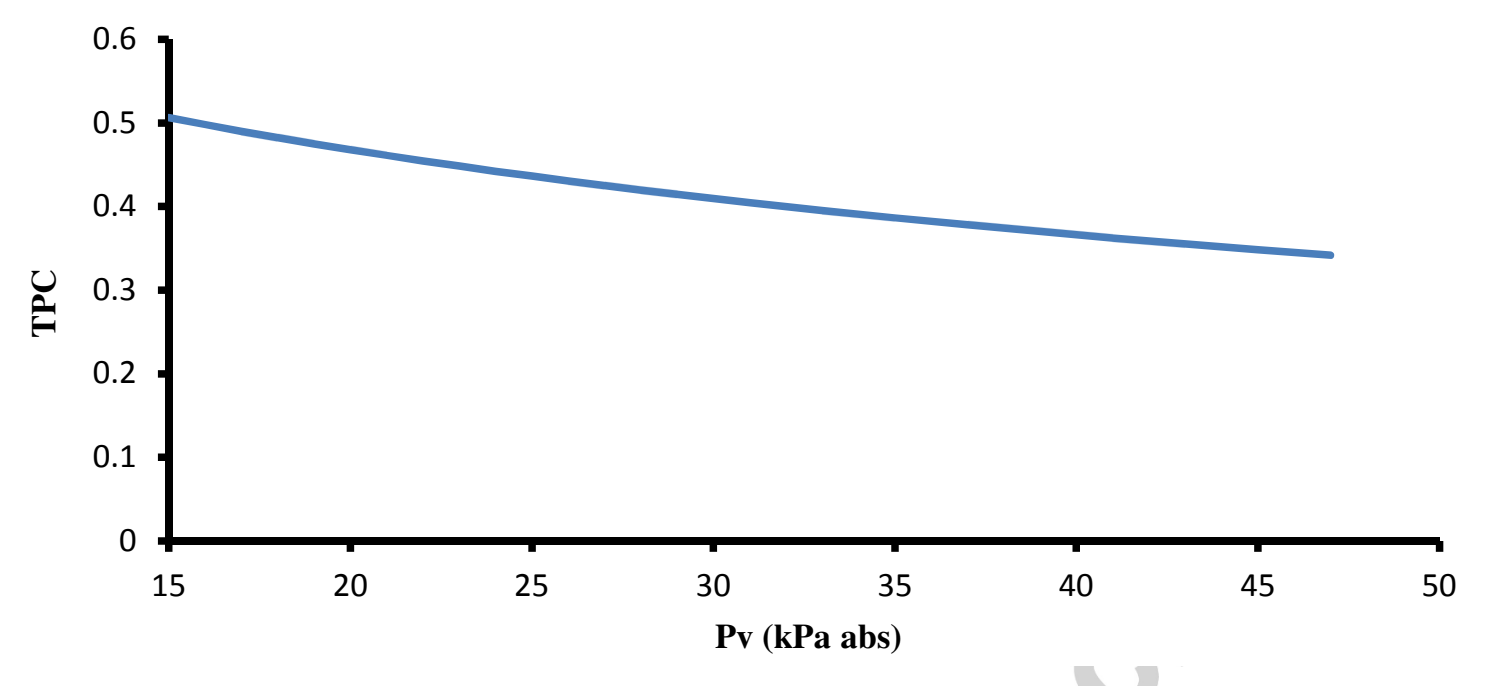

Figure 8: TPC as a function of $\mathrm{P}_{\mathrm{v}}$ at feed temperature of $60^{\circ} \mathrm{C}$ and flow rate of $2 \mathrm{~L} / \mathrm{min}$.

\section{.}

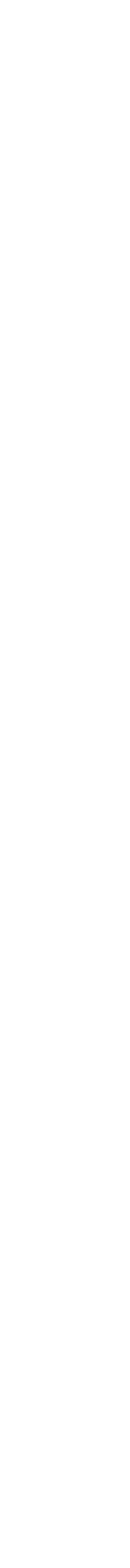

.




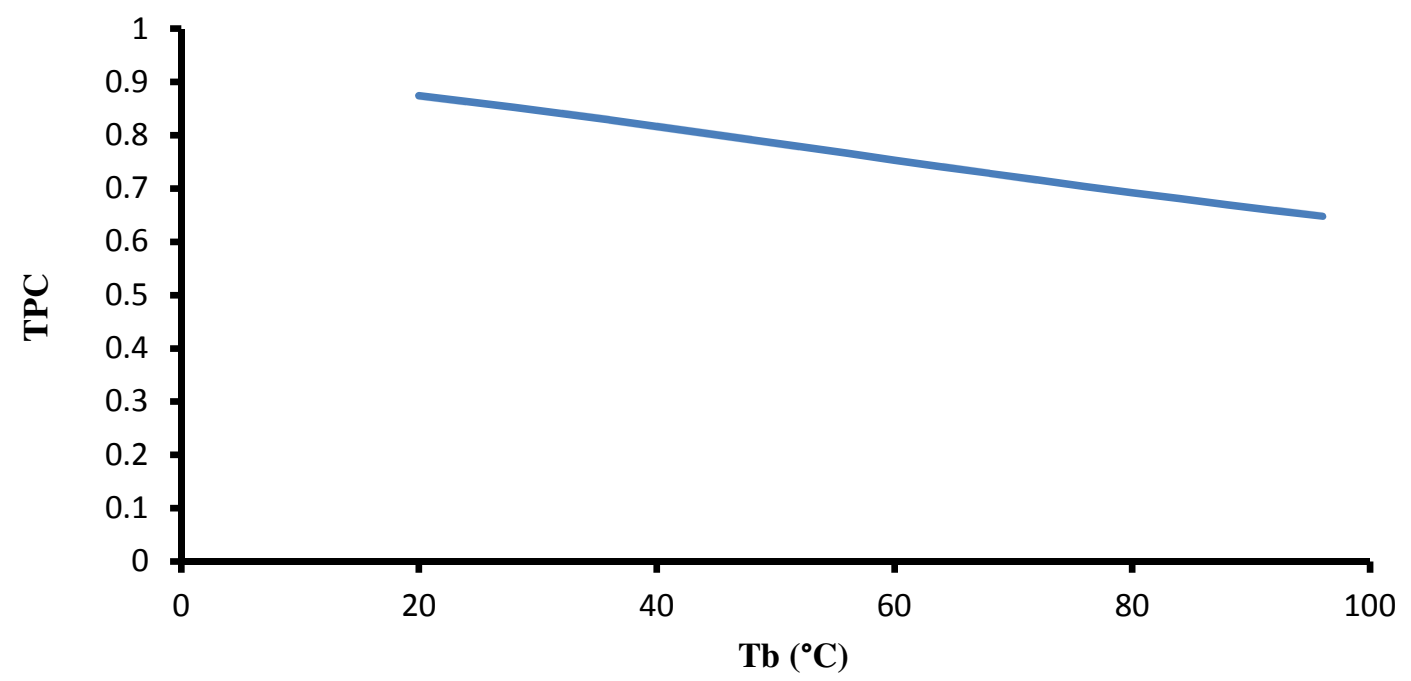

Figure 9: Simulated TPC as a function of $\mathrm{T}_{\mathrm{b}}$ at permeate absolute pressure of $2 \mathrm{kPa}$ and feed flow rate of $2 \mathrm{~L} / \mathrm{min}$. 


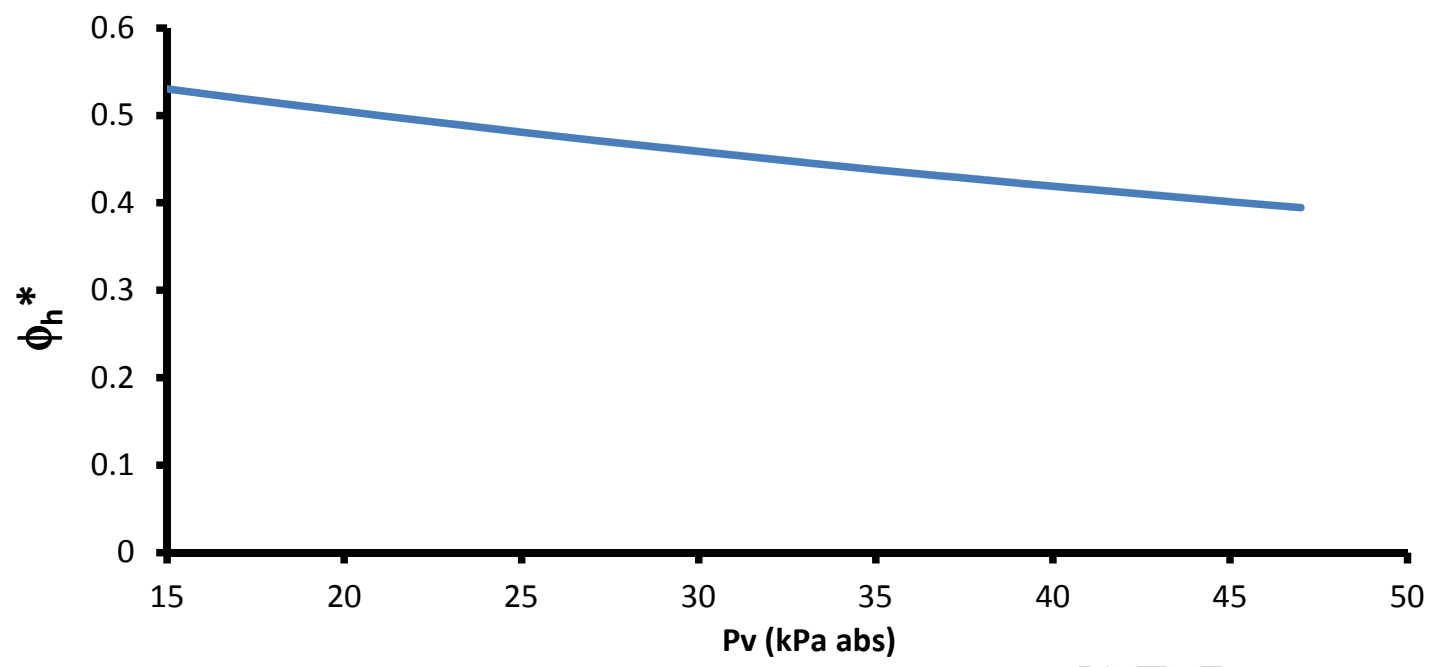

Figure 10: Simulated $\phi_{\mathrm{h}}{ }^{*}$ as a function of $\mathrm{P}_{\mathrm{v}}$ at feed temperature of $60{ }^{\circ} \mathrm{C}$ and flow rate of $2 \mathrm{~L} / \mathrm{min}$. 


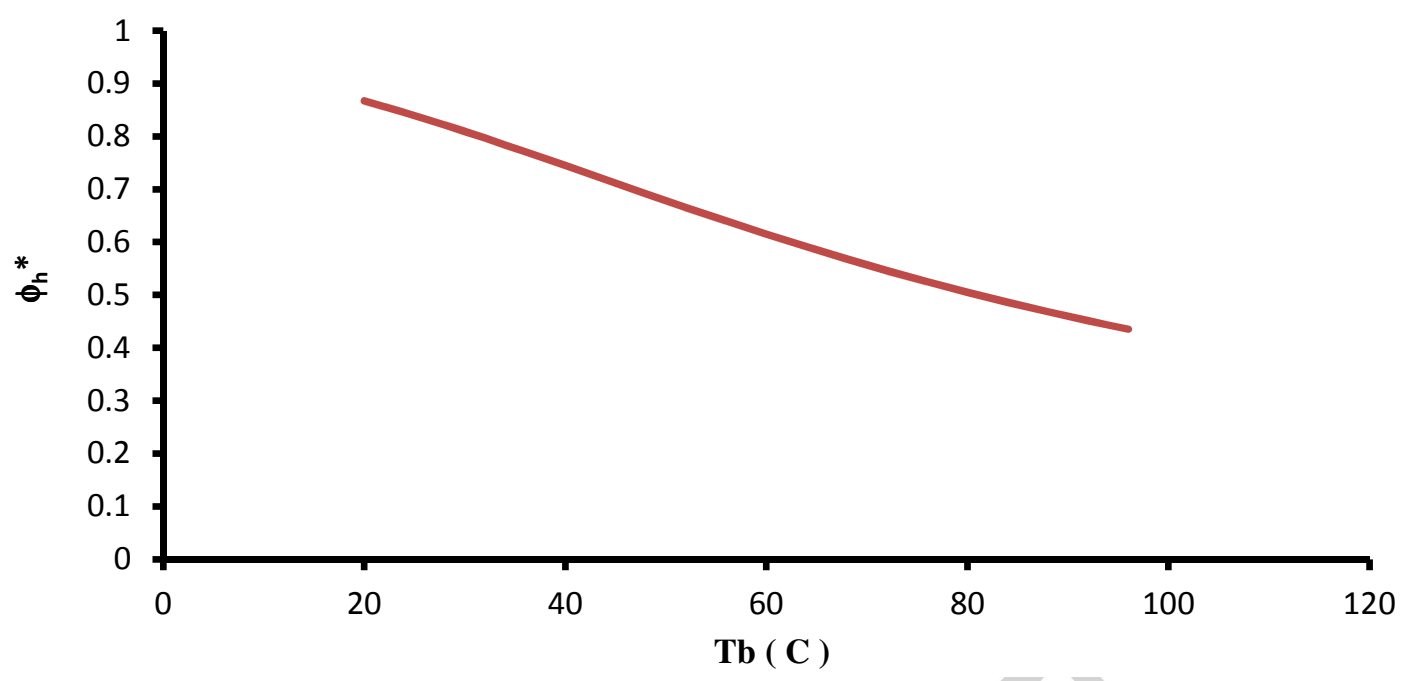

Figure 11: Simulated $\phi_{\mathrm{h}}{ }^{*}$ as a function of $\mathrm{T}_{\mathrm{b}}$ at permeate absolute pressure of $2 \mathrm{kPa}$ and feed flow rate of $2 \mathrm{~L} / \mathrm{min}$. 


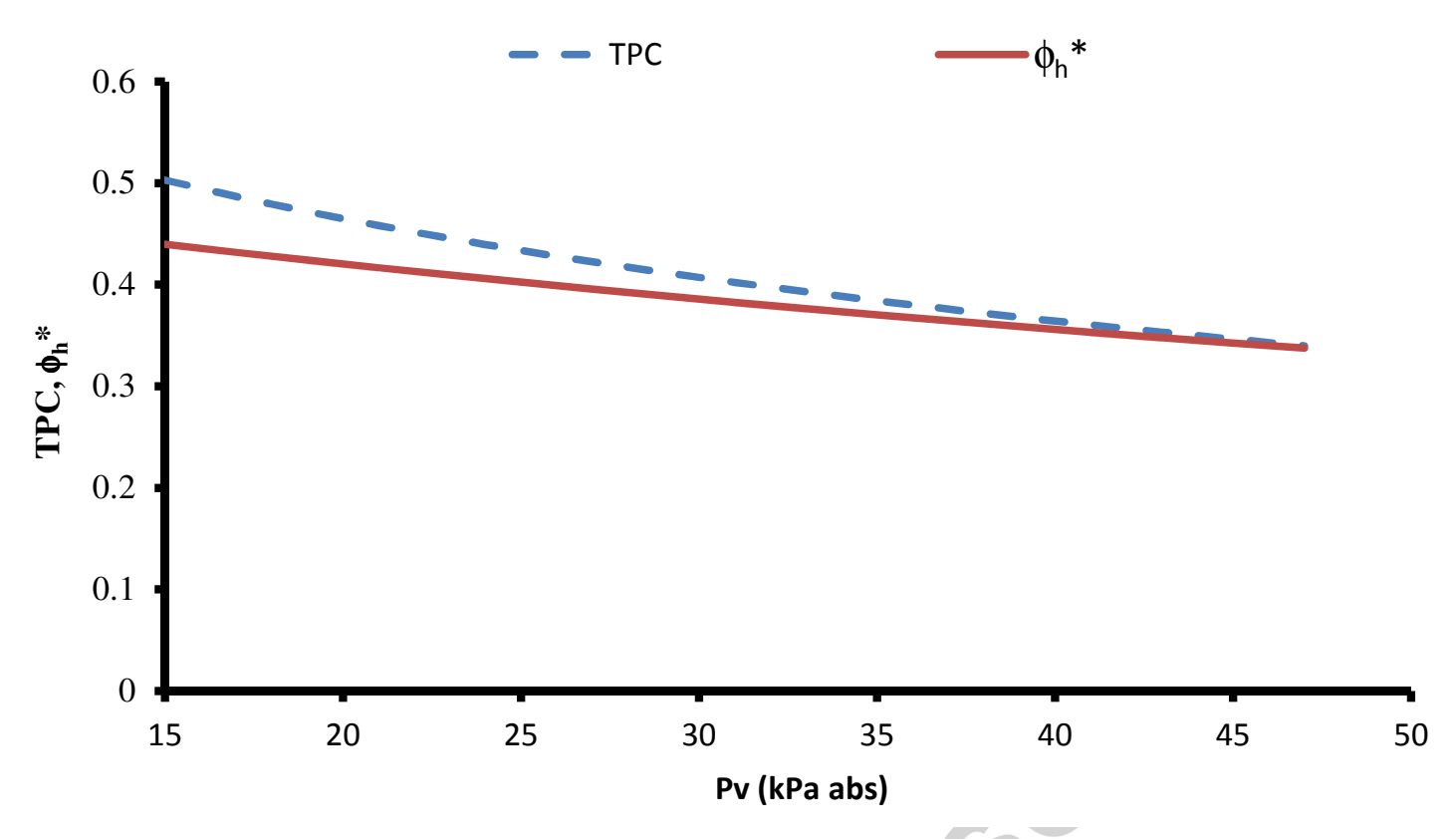

Figure 12: Simulated comparison between TPC and $\phi_{\mathrm{h}} *\left(\mathrm{~T}_{\mathrm{b}}=80^{\circ} \mathrm{C}\right)$

.

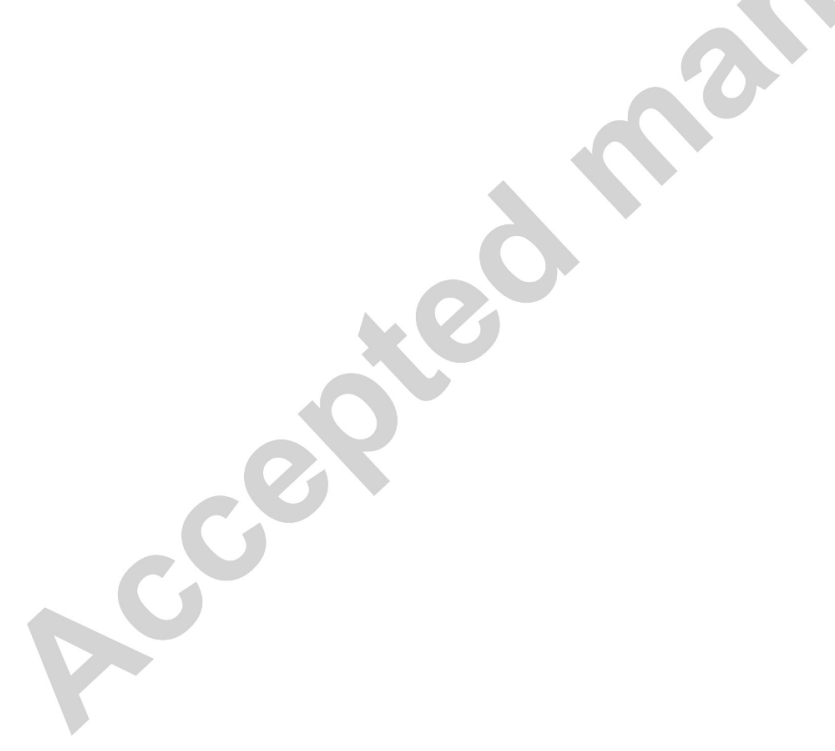




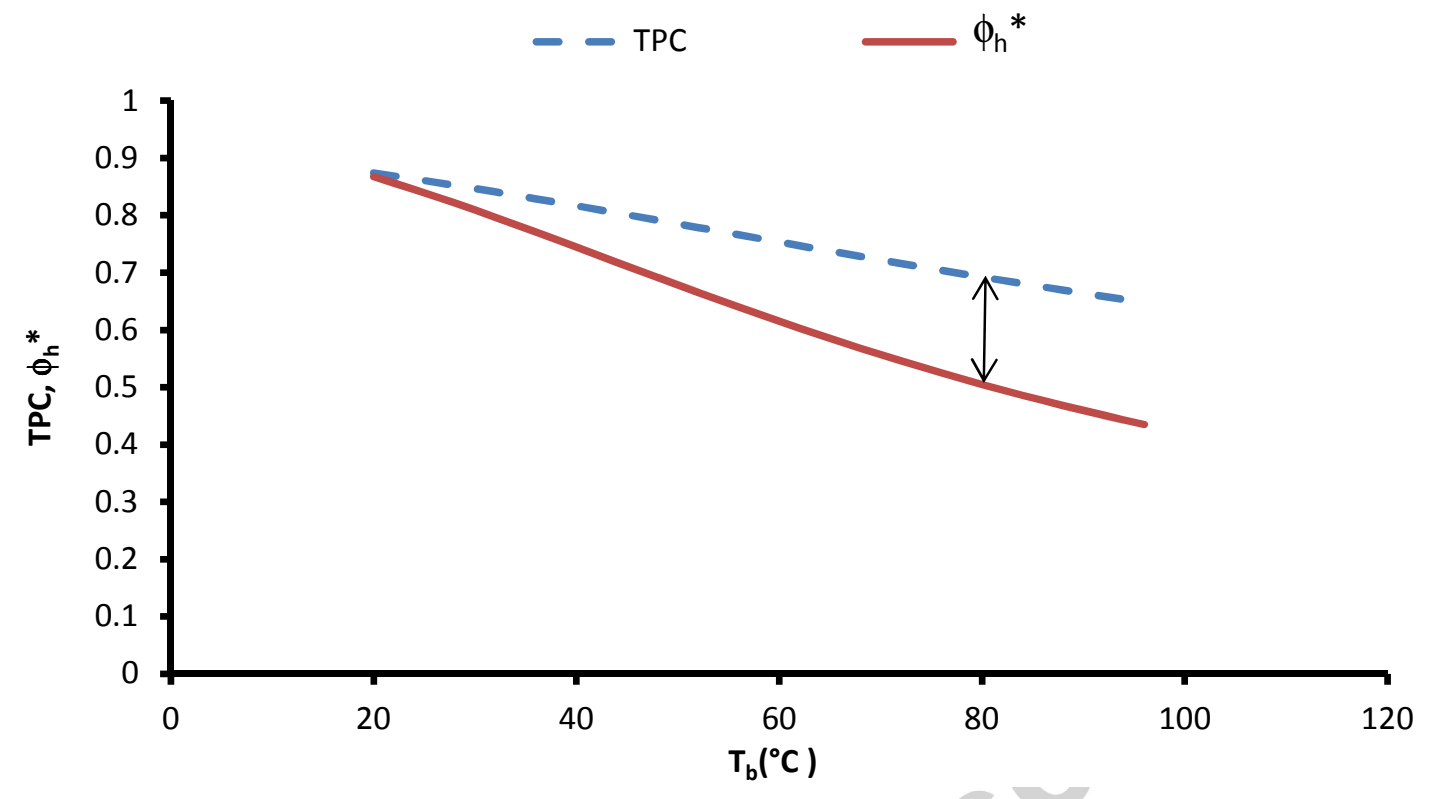

Figure 13: Simulated comparison between TPC and $\phi_{\mathrm{h}} *\left(\mathrm{P}_{\mathrm{v}}=2 \mathrm{kPa}\right)$. 


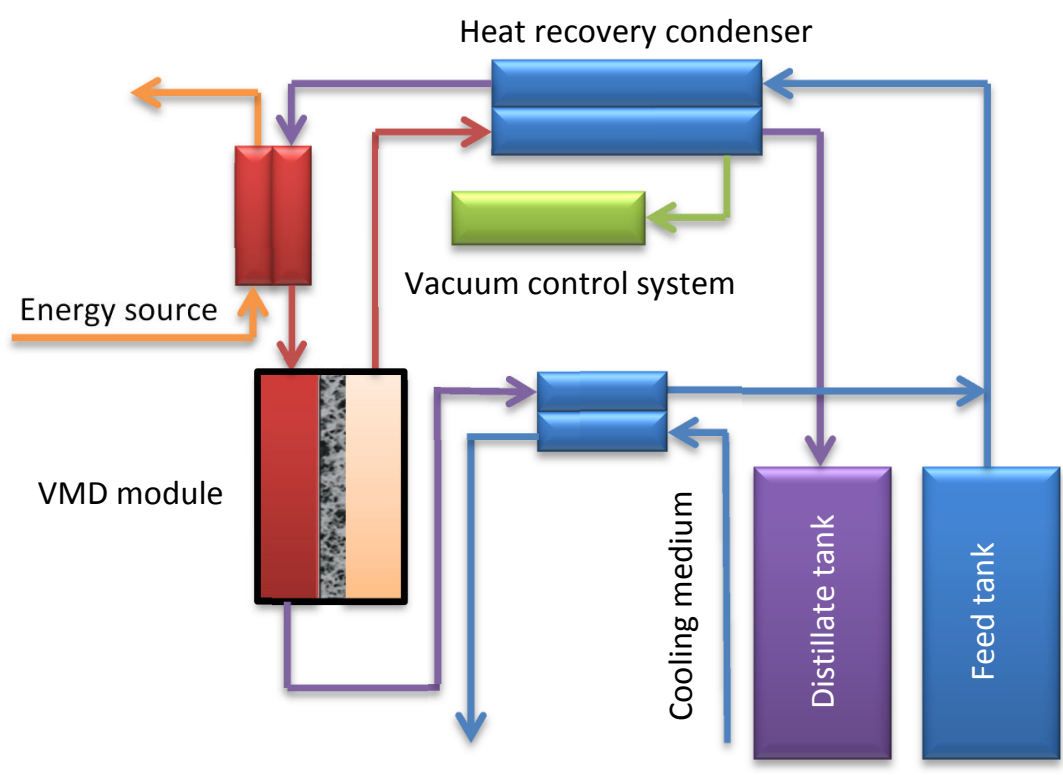

Figure14: Process flow diagram of a heat recovery system integrated to a VMD process. 


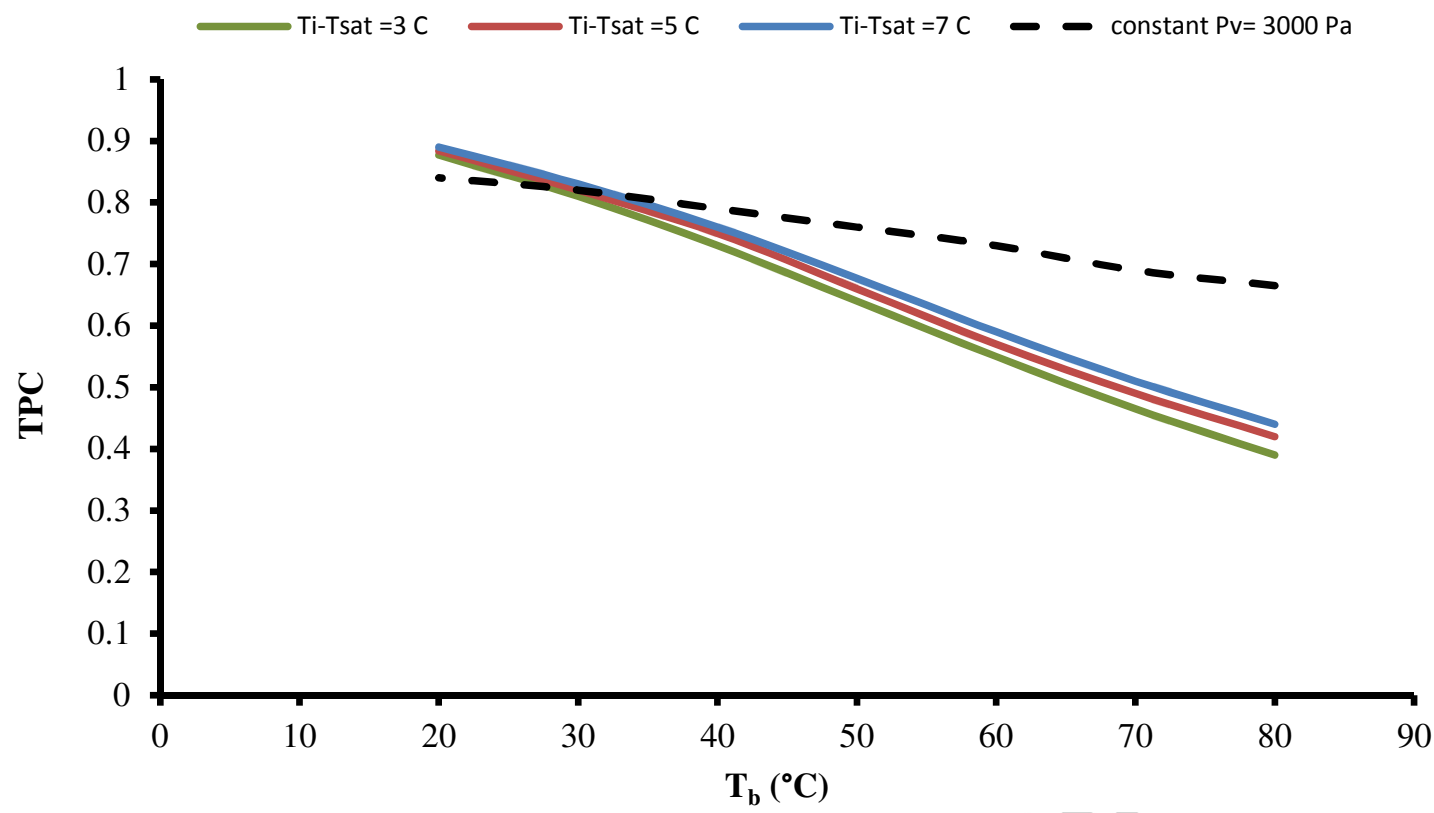

Figure 15: The effect of $\left(\mathrm{T}_{\mathrm{i}}-\mathrm{T}_{\mathrm{sat}}\right)$ on TPC as a function of feed bulk temperature. 